\title{
A New Normal for Interest Rates? Evidence from Inflation-Indexed Debt
}

\author{
Jens H. E. Christensen and Glenn D. Rudebusch \\ Federal Reserve Bank of San Francisco
}

February 2019

Working Paper 2017-07

https://www.frbsf.org/economic-research/publications/working-papers/2017/07/

\section{Suggested citation:}

Christensen, Jens H. E., Glenn D. Rudebusch. 2019. “A New Normal for Interest Rates?

Evidence from Inflation-Indexed Debt,” Federal Reserve Bank of San Francisco Working Paper 2017-07. https://doi.org/10.24148/wp2017-07

The views in this paper are solely the responsibility of the authors and should not be interpreted as reflecting the views of the Federal Reserve Bank of San Francisco or the Board of Governors of the Federal Reserve System. 


\title{
A New Normal for Interest Rates? Evidence from Inflation-Indexed Debt
}

\author{
Jens H. E. Christensen \\ and \\ Glenn D. Rudebusch
}

\begin{abstract}
The downtrend in U.S. interest rates over the past two decades may partly reflect a decline in the longer-run equilibrium real rate of interest. We examine this issue using dynamic term structure models that account for time-varying term and liquidity risk premiums and are estimated directly from prices of individual inflation-indexed bonds. Our finance-based approach avoids two potential pitfalls of previous macroeconomic analyses: structural breaks at the zero lower bound and misspecification of output and inflation dynamics. We estimate that the longer-run equilibrium real rate has fallen about 2 percentage points and appears unlikely to rise quickly.
\end{abstract}

JEL Classification: C32, E43, E52, G12

Keywords: affine arbitrage-free term structure model, U.S. Treasury inflation-protected securities (TIPS), natural rate of interest

\footnotetext{
Jens H. E. Christensen (jens.christensen.sf.frb.org), Glenn D. Rudebusch (glenn.rudebusch@sf.frb.org): Economic Research Department, Federal Reserve Bank of San Francisco, 101 Market Street (MS 1130), San Francisco, CA 94105. We thank Vasco Cúrdia, Leo Krippner, David Romer, Lars Svensson, and three referees for helpful comments as well as many seminar participants and conference participants at the First Marstrand Finance Conference, the IBEFA Summer Meeting, the NBER Summer Institute, the SNB Research Conference, and the Annual Conference of the Swiss Society for Financial Market Research, including our discussants Zary Aftab, Nikola Mirkov, Stefano Neri, and Paul Whelan. Helen Irvin, Patrick Shultz, Logan Tribull, and Dori Wilson provided excellent research assistance. The views in this paper are solely the responsibility of the authors and do not necessarily reflect those of others in the Federal Reserve System.
}

This version: November 29, 2018. 


\section{Introduction}

The general level of U.S. interest rates has gradually but steadily declined over the past few decades. In the 1980s and 1990s, falling inflation was the major impetus for this decline. But more recently, while yields have continued to trend lower, actual inflation as well as survey-based measures of longer-run inflation expectations have stabilized close to 2 percent. Some have argued that the continuing decline in interest rates since 2000 reflects a variety of persistent real-side factors. These real factors - such as slower productivity growth and an aging population - affect global saving and investment and can push down nominal and real yield curves by lowering the steady-state level of the safe short-term real interest rate. ${ }^{1}$ This steady-state real rate is often called the equilibrium or natural or neutral rate of interest and is commonly defined as the short-term real rate of return that would prevail in the absence of transitory disturbances. Other observers, however, have dismissed the evidence for a new lower equilibrium real rate. They downplay the role of persistent real-side factors and argue that yields have been held down recently by temporary factors such as the cyclical headwinds from credit deleveraging in the aftermath of the financial crisis. ${ }^{2}$ So far, this ongoing debate about a possible lower new normal for interest rates has focused on estimates drawn from macroeconomic models and data. In this paper, we use financial models and data to provide an alternative perspective on this issue.

The question of whether the equilibrium real rate has shifted lower is of widespread importance. For investors, the steady-state level of the real short rate serves as an anchor for projections of the future discount rates used in valuing financial assets (e.g., Clarida, 2014, and Bauer and Rudebusch, 2017). For central bankers and economists, the equilibrium or natural rate of interest is a policy lodestar that provides a neutral benchmark to calibrate the stance of monetary policy: Monetary policy is expansionary if the short-term real interest rate lies below the natural rate and contractionary if it lies above. In particular, a good estimate of the equilibrium real rate is necessary to operationalize popular monetary policy rules such as the Taylor rule. ${ }^{3}$

Given the significance of the equilibrium real interest rate, many researchers have used macroeconomic models and data to try to pin it down. The best known of these-Laubach and Williams $(2003,2016$ ) - infers the equilibrium real short rate by using the Kalman filter to distinguish the real interest rate trend and cycle within a model of the above definition of the neutral stance of monetary policy. As Laubach and Williams (2016, p. 57) define the natural rate of interest, it is based on "a 'longer-run' perspective, in that it refers to the

\footnotetext{
${ }^{1}$ See, for example, Rachel and Smith (2015), Gagnon et al. (2016), Hamilton et al. (2016), Laubach and Williams (2016), and Pescatori and Turunen (2016), among many others.

${ }^{2}$ For example, see Kiley (2015), Lo and Rogoff (2015), and Taylor and Wieland (2016).

${ }^{3}$ For research on the role of the natural rate in monetary policy, see Rudebusch (2001), Orphanides and Williams (2002), Eggertsson et al. (2016), and Hamilton et al. (2016), among many others.
} 
level of the real interest rate expected to prevail, say, five to 10 years in the future, after the economy has emerged from any cyclical fluctuations and is expanding at its trend rate." This is precisely the perspective that we will take in this paper, and it is the definition of the natural rate that we will employ, albeit using finance models and data.

However, there are several different conceptual definitions of the equilibrium real rate in the literature. Some researchers focus on a short-run equilibrium rate, which represents the current value of the real rate that would be consistent with the economy at full employment and stable inflation. ${ }^{4}$ Others consider a very long-run empirical equilibrium rate defined as the real rate that would prevail in the infinite future, as calculated, for example, from a statistical trend-cycle decomposition of real rates. In practice, these different definitions appear to be closely related (e.g., Del Negro et al., 2017). As noted above, we focus on an intermediate-term or longer-run definition, namely, the level of the short rate that is expected to prevail after the cyclical imbalances in the economy are expected to work themselves out. Our 5- to 10-year horizon is much shorter than the infinite-horizon steady state but in our view is of particular interest. First, our data sample - like most finite ones - is likely too short to accurately calculate an infinitely distant steady state. Furthermore, there is ample evidence that the 5- to 10-year horizon is particularly relevant for current monetary policy discussions. For example, in the Federal Reserve Board's recent Monetary Policy Report to Congress (2018), a similar forecast horizon underlies the estimated neutral real interest rate used in various monetary policy rules. ${ }^{5}$ More broadly, during the past decade or so, longerrun definitions of a lower new normal for interest rates, like ours, have been at the center of key policy debates about the bond market conundrum, the global saving glut, and secular stagnation. ${ }^{6}$

To construct their macro-based measure of the equilibrium rate, Laubach and Williams (2003, 2016) use the Rudebusch and Svensson (1999) model and data on a nominal short-term interest rate, consumer price inflation, and the output gap. Johannsen and Mertens (2016) and Lubick and Matthes (2015) provide closely related equilibrium rate estimates from a similar filtering of the macroeconomic data, while other macroeconomic researchers, such as Cúrdia et al. (2015), take a more structural approach. However, these and other macrobased approaches for identifying a new lower equilibrium real rate have several potential shortcomings. First, Kiley (2015), Taylor and Wieland (2016), and Lewis and Vazquez-Grande

\footnotetext{
${ }^{4}$ For example, Cúrdia et al. (2015) use a dynamic stochastic general equilibrium (DSGE) model to estimate such a short-run equilibrium rate, which is defined as the real rate that would prevail in a perfectly competitive counterfactual economy with flexible prices and no monopoly power.

${ }^{5}$ For recent Federal Reserve discussions describing the connection between a longer-run neutral or equilibrium rate of interest and monetary policy, see, e.g., Yellen (2015), Fischer (2016), and Nechio and Rudebusch (2016).

${ }^{6}$ See, for example, Greenspan (2005), Bernanke (2005), and Summers (2014, 2015), respectively, on these three debates.
} 
(2017) note that the macro-based estimates of the natural rate can be distorted by model misspecifications, especially in the assumed output and inflation dynamics. Kiley, for example, suggests that the output equation in Laubach and Williams is missing an important credit spread variable. Such model misspecifications could also arise from overlooking structural shifts or regime changes during the sample. This is a serious concern in the aftermath of the Great Recession when nominal interest rates were constrained by the lower bound near zeroa nonlinearity that likely affects the dynamic correlations between nominal interest rates and output. Furthermore, Kiley (2015) argues that the key intertemporal IS curve/Euler equation correlation between real interest rates and output, which is crucial for pinning down macrobased estimates of the natural rate, is a weak empirical foundation for this analysis. Finally, as noted by Clark and Kozicki (2005), a macro-based approach may face a number of problems from the standpoint of a real-time analysis. For example, macro-based analyses often use extensively-revised output and inflation data to create equilibrium real rate estimates that would not have been available historically. In addition, a one-sided macro-based filtering that could be applied in real time is completely backward-looking and may face difficulties in distinguishing persistent shifts in the economy that affect the natural rate from cyclical and transitory fluctuations.

Given these potential pitfalls of a macro-based estimation, we turn to financial models and data to provide an alternative approach to estimate the equilibrium real rate of interest. We use the prices of inflation-indexed debt, namely, U.S. Treasury Inflation-Protected Securities (TIPS). These securities have coupon and principal payments that adjust for changes in the Consumer Price Index (CPI) and thus compensate investors for the erosion of purchasing power due to inflation. The prices of these securities can provide a fairly direct reading on real yields since 1997 when the TIPS program was launched. We assume that the longerterm expectations embedded in TIPS prices reflect financial market participants' views about the steady state of the economy including the equilibrium interest rate. ${ }^{7}$ Our finance-based measure of the natural rate has several potential advantages relative to the macro-based estimates. Most notably, our measure of the equilibrium rate does not depend on obtaining a correct specification of the output and inflation dynamics - unlike previous estimates that rely on a specific macroeconomic representation. Furthermore, our measure can be obtained in real time at the same high frequency as the underlying bond price data, and it is based on financial market data and so is naturally forward-looking.

Still, the use of TIPS for measuring the steady-state short-term real interest rate poses its own empirical challenges. One difficulty is that inflation-indexed bond prices include a real term premium. Given the generally upward slope of the TIPS yield curve, the real term

\footnotetext{
${ }^{7}$ See Bomfim (2001) for an early model-free discussion of this issue. Also, Joyce et al. (2012) use dynamic term structure models of U.K. index-linked government yields to study long-term real rate expectations while accounting for real term premiums though not liquidity premiums.
} 
premium appears positive on average, but its variability is unknown. In addition, despite the fairly large notional amount of outstanding TIPS, these securities arguably face appreciable liquidity risk. For example, Fleming and Krishnan (2012) report that TIPS usually have a smaller trading volume and wider bid-ask spreads than nominal Treasury bonds. Presumably, investors require a premium for bearing the liquidity risk associated with holding TIPS, but the size and variability of this liquidity premium are also hard to pin down. ${ }^{8}$

To estimate the equilibrium rate of interest in the presence of liquidity and real term premiums, we use arbitrage-free dynamic term structure models of real yields. The theoretical arbitrage-free formulation of the model provides identification of a time-varying real term premium in the pricing of TIPS. In addition, our model is estimated using the prices of individual bonds rather than the more usual input of yields from fitted synthetic curves. Our methodology contrasts with previous term structure models, which are almost universally estimated on synthetic zero-coupon yields obtained from fitted yield curves. However, the use of interpolated yield curves in term structure analysis can introduce unnecessary measurement error. ${ }^{9}$ Avoiding interpolated bond yields appears particularly useful for analyzing situations with only a limited sample of bonds as is often the case for inflation-indexed debt.

For robustness, we consider two different dynamic term structure models. One is more standard with no separate explicit treatment of the liquidity premium - term and liquidity risks are implicitly modeled together. The second model is augmented with an explicit liquidity risk factor. This model identifies an overall TIPS liquidity factor and each individual bond's loading on that factor from the cross section of TIPS prices over time - with each security possessing a different time-since-issuance and time-to-maturity. The identification of the overall liquidity risk factor comes from its unique loading for each individual TIPS as in Andreasen et al. (2018, henceforth ACR). This loading assumes that, over time, an increasing proportion of the outstanding inventory is locked up in buy-and-hold portfolios. Given forward-looking investor behavior, this lock-up effect implies that a particular bond's sensitivity to the market-wide liquidity factor will vary depending on how seasoned the bond is and how close to maturity it is. Fontaine and Garcia (2012) provide empirical support for such an approach as they uncover a pervasive liquidity factor that affects nominal Treasury prices with loadings that vary with the maturity and age of each bond.

Our two models complement each other. The first is a parsimonious representation of TIPS prices, while the second is a highly parameterized specification that can provide sharper inference -if the underlying assumed structure is appropriate. After using these models to

\footnotetext{
${ }^{8}$ See, for example, Sack and Elsasser (2004), Campbell et al. (2009), Dudley et al. (2009), Gürkaynak et al. (2010), Fleckenstein et al. (2014), Driessen, et al. (2016), and Pflueger and Viceira (2016).

${ }^{9}$ Fontaine and Garcia (2012) argue that the use of such synthetic yields can erase useful information on liquidity effects. Dai et al. (2004) found notable differences in empirical results across four different yield curve interpolation schemes. For further discussion of these issues, see Andreasen et al. (2019).
} 


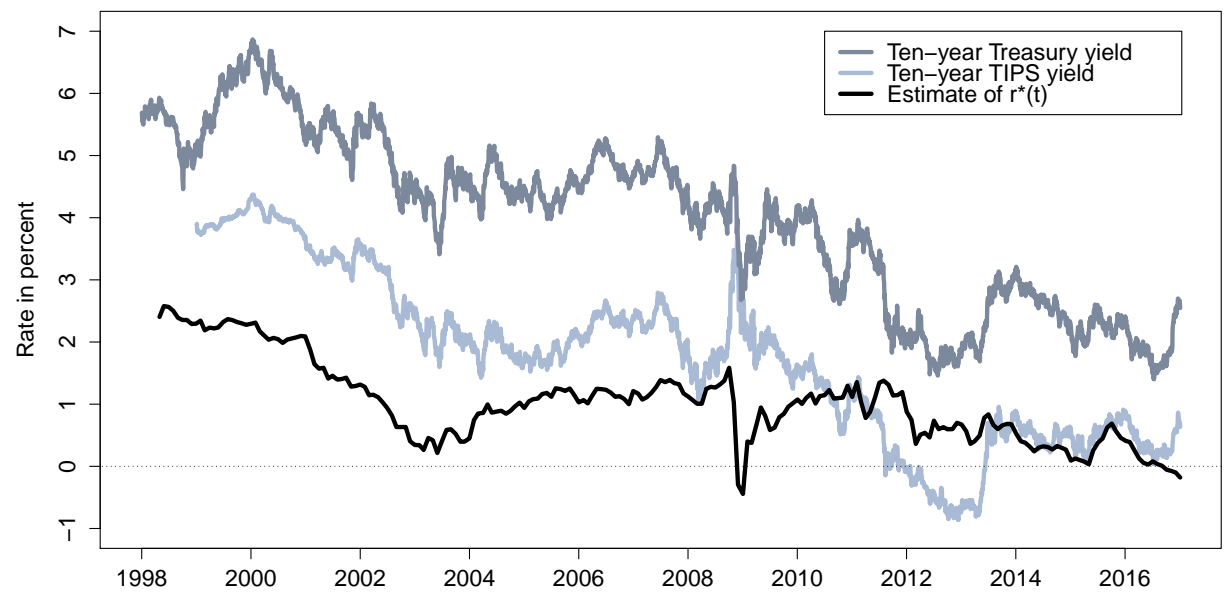

Figure 1: Long-Term Treasury and TIPS Yields and an Estimate of $\mathbf{r}^{*}$

Ten-year nominal and real (TIPS) Treasury yields from the Gürkaynak et al. (2007, 2010) databases and our preferred finance-based measure of the equilibrium real short rate, $r_{t}^{*}$, which is defined as the 5-to-10 year risk-neutral real rate and measured as an average of two model estimates.

identify the relevant bond premiums, we can estimate the underlying real rate term structure and the natural rate of interest, which we define as the average expected real short rate over a five-year period starting five years ahead - consistent with the Laubach and Williams (2016) longer-run perspective noted above. Our preferred measure of the natural rate of interest, $r_{t}^{*}$, is shown in Figure 1 along with 10-year nominal and real Treasury yields. This measure is an average of the estimates from the two models. Both nominal and real long-term yields have trended down together over the past two decades, and this concurrence suggests little net change in inflation expectations or the inflation risk premium. The estimated equilibrium real rate has fallen from just over 2 percent to near zero during this period. Accordingly, our results show that about half of the 4-percentage-point decline in longer-term Treasury yields over the past two decades represents a reduction in the natural rate of interest. Our model estimates also suggest that this situation is unlikely to reverse quickly in the years ahead.

Our focus on a TIPS-only analysis contrasts with past TIPS research that has jointly modeled both the real and nominal yield curves, as in, for example, Christensen et al. (2010), Abrahams et al. (2016, henceforth AACMY), and D'Amico et al. (2018). Such joint specifications can also be used to estimate the steady-state real rate - although this earlier work has emphasized only the measurement of inflation expectations and the inflation risk premium. The earlier investigations that include both real and nominal yields have advantages and disadvantages relative to our procedure of using only TIPS. A joint modeling approach is able 
to estimate a model on a much longer and larger sample of bond yields. It also can be used to explore whether the estimated linkages among real and nominal interest rates, inflation expectations, and risk premiums have counterfactual model implications for these variables.

However, a joint specification also requires additional modeling structure -including specifying more pricing factors, an inflation risk premium, and inflation expectations. The greater number of modeling elements - along with the requirement that this more elaborate structure remains stable over the sample - raise the risk of model misspecification, which can contaminate estimates of the natural rate and model inference more generally. In particular, if the inflation components are misspecified, the whole dynamic system may be compromised. Furthermore, during the period from 2009 to 2015 when the Federal Reserve kept the overnight federal funds rate at its effective zero lower bound, the dynamic interactions of short- and medium-term nominal Treasury yields were affected. The zero lower bound is difficult to incorporate in an empirical term structure model of nominal yields (see Christensen and Rudebusch 2015 for discussion). By relying solely on real TIPS yields, we minimize the implications of this constraint. Still, for completeness, we do compare our TIPS-only estimates to the natural rate estimates from existing joint representations of the real and nominal yield curves.

The remainder of the paper is organized as follows. Section 2 describes our definition of the natural rate and our theoretical framework. This section describes our no-arbitrage term structure models including the version that includes a liquidity risk factor. Section 3 contains a description of the TIPS data, while Section 4 discusses econometric identification and the empirical results. Section 5 analyzes our TIPS-based measures of the natural rate and compares them to previous estimates. Finally, Section 6 concludes. Online appendices available from the authors contain additional technical details on TIPS pricing and characteristics, the model estimation, and various robustness checks.

\section{Identifying the Natural Rate of Interest with TIPS}

In this section, we first describe how real bond yields can be decomposed into the underlying real rate expectations component and a residual real term premium in a world without any trading frictions. This model of frictionless dynamics is fundamental to our analysis. We then describe a potential wedge between the theoretical frictionless real yields and the observed TIPS yields caused by imperfect bond market liquidity. Finally, we augment the frictionless model to adjust TIPS yields for the liquidity bias. 


\subsection{Decomposing Real Yields with Frictionless Affine Models}

We begin our analysis assuming a world with no frictions to the trading of financial claims; therefore, there are no bid-ask spreads, and any financial claim can be traded in arbitrarily small or large amounts without affecting its price. As a consequence, with no liquidity risk to be rewarded, financial market prices contain no liquidity premiums. Under such ideal conditions, real yields vary either because fundamental factors in the economy have changed or because investors have altered their perceptions of, or aversions to, the risks that those economic fundamentals represent.

Assessing the variation in real yields caused by time-varying real term premiums requires an accurate model of expectations for the instantaneous risk-free real rate $r_{t}$ and the term premium. For simplicity, we focus on decomposing $P_{t}(\tau)$, the price of a zero-coupon real bond at time $t$ that has a single payoff, namely one consumption unit, at maturity $t+\tau$. Under standard assumptions, this price is given by

$$
P_{t}(\tau)=E_{t}^{\mathbb{P}}\left[\frac{M_{t+\tau}}{M_{t}}\right]
$$

where the stochastic discount factor, $M_{t}$, denotes the value at time $t_{0}$ of a real claim (one measured in consumption units) at a future date $t$, and the superscript $\mathbb{P}$ refers to the actual, or real-world, probability measure underlying the dynamics of $M_{t}$.

Our working definition of the equilibrium rate of interest $r_{t}^{*}$ is

$$
r_{t}^{*}=\frac{1}{5} \int_{t+5}^{t+10} E_{t}^{\mathbb{P}}\left[r_{t+s}\right] d s
$$

that is, the average expected real short rate over a five-year period starting five years ahead where the expectation is with respect to the objective $\mathbb{P}$-probability measure. ${ }^{10}$ As noted in the introduction, such a medium-run horizon is of particular interest to policymakers. The 5yr5yr forward average expected real short rate is a long enough horizon to be little affected by short-term transitory shocks but a short enough one to be plausibly pinned down by the available evidence. Alternatively, $r_{t}^{*}$ could be defined as the expected real short rate at an infinite horizon (that is, as $E_{t}^{\mathbb{P}}\left[r_{t+\infty}\right]$ as in Johannsen and Mertens, 2016, and Lubick and Matthes, 2015). However, quantifying this endpoint is arguably quite difficult as it depends crucially on whether the factor dynamics are assumed to exhibit a unit root. Our model follows the finance literature and adopts a stationary structure, so strictly speaking, our infinite-horizon steady state expected real rate is constant. In general, we do not view our data sample as having sufficient information in the 10-year to infinite-horizon range to

\footnotetext{
${ }^{10}$ In the appendix available upon request, we consider alternative horizons to define $r_{t}^{*}$ and find our results to be representative.
} 
definitively pin down the steady state, so we prefer our definition that uses a medium- to longer-run horizon. ${ }^{11}$

In the empirical analysis, we rely on the market prices of TIPS to construct this marketbased measure of the natural rate. In doing so, it is important to acknowledge that financial market prices do not reflect objective $\mathbb{P}$-expectations as in equation (1). Instead, they reflect expectations adjusted with the premiums investors demand for being exposed to the underlying risks. We follow the usual empirical finance approach that models bond prices with latent factors, here denoted as $X_{t}$, and the assumption of no residual arbitrage opportunities. ${ }^{12}$ We assume that $X_{t}$ follows an affine Gaussian process with constant volatility, with dynamics in continuous time given by the solution to the following stochastic differential equation (SDE):

$$
d X_{t}=K^{\mathbb{P}}\left(\theta^{\mathbb{P}}-X_{t}\right)+\Sigma d W_{t}^{\mathbb{P}}
$$

where $K^{\mathbb{P}}$ is an $n \times n$ mean-reversion matrix, $\theta^{\mathbb{P}}$ is an $n \times 1$ vector of mean levels, $\Sigma$ is an $n \times n$ volatility matrix, and $W_{t}^{\mathbb{P}}$ is an $n$-dimensional Brownian motion. The dynamics of the stochastic discount function are given by

$$
d M_{t}=r_{t} M_{t} d t+\Gamma_{t}^{\prime} M_{t} d W_{t}^{\mathbb{P}}
$$

and the instantaneous risk-free real rate, $r_{t}$, is assumed affine in the state variables

$$
r_{t}=\delta_{0}+\delta_{1} X_{t}
$$

where $\delta_{0} \in \mathbf{R}$ and $\delta_{1} \in \mathbf{R}^{n}$. The risk premiums, $\Gamma_{t}$, are also affine

$$
\Gamma_{t}=\gamma_{0}+\gamma_{1} X_{t}
$$

where $\gamma_{0} \in \mathbf{R}^{n}$ and $\gamma_{1} \in \mathbf{R}^{n \times n}$.

Duffie and Kan (1996) show that these assumptions imply that zero-coupon real yields are also affine in $X_{t}$ :

$$
y_{t}(\tau)=-\frac{1}{\tau} A(\tau)-\frac{1}{\tau} B(\tau)^{\prime} X_{t}
$$

where $A(\tau)$ and $B(\tau)$ are given as solutions to the following system of ordinary differential

\footnotetext{
${ }^{11}$ As is well known, the typical spans of available time series data do not distinguish strongly between highly persistent stationary processes and non-stationary ones (Rudebusch, 1993). In the appendix available upon request, we show that our main results are robust to an alternative assumption of a unit root in the factor dynamics.

${ }^{12}$ Ultimately, of course, the behavior of the stochastic discount factor is determined by the preferences of the agents in the economy, as in, for example, Rudebusch and Swanson (2011).
} 
equations

$$
\begin{aligned}
& \frac{d B(\tau)}{d \tau}=-\delta_{1}-\left(K^{\mathbb{P}}+\Sigma \gamma_{1}\right)^{\prime} B(\tau), \quad B(0)=0, \\
& \frac{d A(\tau)}{d \tau}=-\delta_{0}+B(\tau)^{\prime}\left(K^{\mathbb{P}} \theta^{\mathbb{P}}-\Sigma \gamma_{0}\right)+\frac{1}{2} \sum_{j=1}^{n}\left(\Sigma^{\prime} B(\tau) B(\tau)^{\prime} \Sigma\right)_{j, j}, \quad A(0)=0 .
\end{aligned}
$$

Thus, the $A(\tau)$ and $B(\tau)$ functions are calculated as if the dynamics of the state variables had a constant drift term equal to $K^{\mathbb{P}} \theta^{\mathbb{P}}-\Sigma \gamma_{0}$ instead of the actual $K^{\mathbb{P}} \theta^{\mathbb{P}}$ and a mean-reversion matrix equal to $K^{\mathbb{P}}+\Sigma \gamma_{1}$ as opposed to the actual $K^{\mathbb{P}} \cdot{ }^{13}$ The difference is determined by the risk premium $\Gamma_{t}$ and reflects investors' aversion to the risks embodied in $X_{t}$.

Finally, we define the real term premium as

$$
T P_{t}(\tau)=y_{t}(\tau)-\frac{1}{\tau} \int_{t}^{t+\tau} E_{t}^{\mathbb{P}}\left[r_{s}\right] d s
$$

That is, the real term premium is the difference in expected real return between a buy and hold strategy for a $\tau$-year real bond and an instantaneous rollover strategy at the risk-free real rate $r_{t}$. This model thus decomposes yields into a real term premium and real short rate expectations component, which can then be used to obtain the natural rate via equation (1).

\section{$2.2 \quad$ A Frictionless Arbitrage-Free Model of Real Yields}

To capture the fundamental factors operating the frictionless real yield curve described above, we choose to focus on the tractable affine dynamic term structure model introduced in Christensen et al. (2011). Although the model is not formulated using the canonical form of affine term structure models introduced by Dai and Singleton (2000), it can be viewed as a restricted version of the canonical Gaussian model. ${ }^{14}$

In this arbitrage-free Nelson-Siegel (AFNS) model, the state vector is denoted by $X_{t}=$ $\left(L_{t}, S_{t}, C_{t}\right)$, where $L_{t}$ is a level factor, $S_{t}$ is a slope factor, and $C_{t}$ is a curvature factor. The instantaneous risk-free real rate is defined as

$$
r_{t}=L_{t}+S_{t}
$$

The risk-neutral (or $\mathbb{Q}$-) dynamics of the state variables are given by the stochastic differential

\footnotetext{
${ }^{13}$ The probability measure with these alternative dynamics is frequently referred to as the risk-neutral, or $\mathbb{Q}$, probability measure since the expected return on any asset under this measure is equal to the risk-free real rate $r_{t}$ that a risk-neutral investor would demand.

${ }^{14}$ See Christensen et al. (2011) for details on the derivation of the restrictions.
} 
equations $^{15}$

$$
\left(\begin{array}{c}
d L_{t} \\
d S_{t} \\
d C_{t}
\end{array}\right)=\left(\begin{array}{ccc}
0 & 0 & 0 \\
0 & -\lambda & \lambda \\
0 & 0 & -\lambda
\end{array}\right)\left(\begin{array}{c}
L_{t} \\
S_{t} \\
C_{t}
\end{array}\right) d t+\Sigma\left(\begin{array}{c}
d W_{t}^{L, \mathbb{Q}} \\
d W_{t}^{S, \mathbb{Q}} \\
d W_{t}^{C, \mathbb{Q}}
\end{array}\right)
$$

where $\Sigma$ is the constant covariance (or volatility) matrix. ${ }^{16}$ Based on this specification of the $\mathbb{Q}$-dynamics, zero-coupon real bond yields preserve the Nelson-Siegel factor loading structure as

$$
y_{t}(\tau)=L_{t}+\left(\frac{1-e^{-\lambda \tau}}{\lambda \tau}\right) S_{t}+\left(\frac{1-e^{-\lambda \tau}}{\lambda \tau}-e^{-\lambda \tau}\right) C_{t}-\frac{A(\tau)}{\tau},
$$

where the yield-adjustment term is given by

$$
\begin{aligned}
\frac{A(\tau)}{\tau}= & \frac{\sigma_{11}^{2}}{6} \tau^{2}+\sigma_{22}^{2}\left[\frac{1}{2 \lambda^{2}}-\frac{1}{\lambda^{3}} \frac{1-e^{-\lambda \tau}}{\tau}+\frac{1}{4 \lambda^{3}} \frac{1-e^{-2 \lambda \tau}}{\tau}\right] \\
& +\sigma_{33}^{2}\left[\frac{1}{2 \lambda^{2}}+\frac{1}{\lambda^{2}} e^{-\lambda \tau}-\frac{1}{4 \lambda} \tau e^{-2 \lambda \tau}-\frac{3}{4 \lambda^{2}} e^{-2 \lambda \tau}+\frac{5}{8 \lambda^{3}} \frac{1-e^{-2 \lambda \tau}}{\tau}-\frac{2}{\lambda^{3}} \frac{1-e^{-\lambda \tau}}{\tau}\right] .
\end{aligned}
$$

To complete the description of the model and to implement it empirically, we will need to specify the risk premiums that connect these factor dynamics under the $\mathbb{Q}$-measure to the dynamics under the real-world (or physical) $\mathbb{P}$-measure. It is important to note that there are no restrictions on the dynamic drift components under the empirical $\mathbb{P}$-measure beyond the requirement of constant volatility. To facilitate empirical implementation, we use the essentially affine risk premium specification introduced in Duffee (2002). In the Gaussian framework, this specification implies that the risk premiums $\Gamma_{t}$ depend on the state variables; that is,

$$
\Gamma_{t}=\gamma^{0}+\gamma^{1} X_{t}
$$

where $\gamma^{0} \in \mathbf{R}^{3}$ and $\gamma^{1} \in \mathbf{R}^{3 \times 3}$ contain unrestricted parameters.

Thus, the resulting unrestricted three-factor AFNS model has $\mathbb{P}$-dynamics given by

$$
\left(\begin{array}{c}
d L_{t} \\
d S_{t} \\
d C_{t}
\end{array}\right)=\left(\begin{array}{ccc}
\kappa_{11}^{\mathbb{P}} & \kappa_{12}^{\mathbb{P}} & \kappa_{13}^{\mathbb{P}} \\
\kappa_{21}^{\mathbb{P}} & \kappa_{22}^{\mathbb{P}} & \kappa_{23}^{\mathbb{P}} \\
\kappa_{31}^{\mathbb{P}} & \kappa_{32}^{\mathbb{P}} & \kappa_{33}^{\mathbb{P}}
\end{array}\right)\left(\left(\begin{array}{c}
\theta_{1}^{\mathbb{P}} \\
\theta_{2}^{\mathbb{P}} \\
\theta_{3}^{\mathbb{P}}
\end{array}\right)-\left(\begin{array}{c}
L_{t} \\
S_{t} \\
C_{t}
\end{array}\right)\right) d t+\Sigma\left(\begin{array}{c}
d W_{t}^{L, \mathbb{P}} \\
d W_{t}^{S, \mathbb{P}} \\
d W_{t}^{C, \mathbb{P}}
\end{array}\right) .
$$

This is the transition equation in the Kalman filter estimation. We will denote this representation as the TIPS-only (T-O) model.

\footnotetext{
${ }^{15}$ As discussed in Christensen et al. (2011), with a unit root in the level factor, the model is not arbitragefree with an unbounded horizon; therefore, as is often done in theoretical discussions, we impose an arbitrary maximum horizon.

${ }^{16}$ As per Christensen et al. (2011), $\Sigma$ is a diagonal matrix, and $\theta^{\mathbb{Q}}$ is set to zero without loss of generality.
} 


\subsection{An Arbitrage-Free Model of Real Yields with Liquidity Risk}

Equation (2) highlights that the decomposition of real yields into expectations and risk premium components can be affected if the observed real yields incorporate a premium for liquidity risk. As is common in the literature, the T-O model above has no separate explicit treatment of this risk. Instead, term and liquidity risk premiums are implicitly modeled together. In this section, we augment the T-O model to explicitly account for this liquidity risk. By adjusting the TIPS prices for liquidity effects we obtain alternative estimates of the real yield decomposition in equation (2), which ultimately provides us with readings of the natural rate as defined in equation (1). A very narrow interpretation of liquidity risk focuses on the uncertain cost of quickly selling a bond. More broadly, liquidity risk is a catch-all term to account for the transactional frictions that lead to deviations from the law of one price. In this regard, Fontaine and Garcia (2012) highlight the funding requirements faced by bond arbitrageurs and the variation over time in the cost of funding liquidity, say, via the repo market.

We assume that due to liquidity risk, TIPS yields are sensitive to liquidity pressures. As a consequence, the discounting of their future cash flows is not performed with the frictionless real discount function described in Section 2.1, but rather with a discount function that also accounts for liquidity risk. Recent research by $\mathrm{Hu}$ et al. (2013) and others suggest that liquidity is indeed a priced risk factor. Thus, we follow ACR and assume a single liquidity risk factor denoted $X_{t}^{l i q} .{ }^{17}$ Furthermore, the ACR approach assumes liquidity risk is securityspecific in nature. Indeed, we use a unique function to discount the cash flow of each TIPS indexed $i$ :

$$
\bar{r}_{t}^{i}=r_{t}+\beta^{i}\left(1-e^{-\lambda^{L, i}\left(t-t_{0}^{i}\right)}\right) X_{t}^{l i q},
$$

where $r_{t}$ is the frictionless instantaneous real rate, $t_{0}^{i}$ denotes the date of issuance of the security, $\beta^{i}$ is its sensitivity to the variation in the liquidity risk factor, and $\lambda^{L, i}$ is a decay parameter. While all of the sensitivities could be identical, ACR show that it is important to allow for the possibility that they vary across individual securities. Furthermore, we allow the decay parameter $\lambda^{L, i}$ to vary across securities as well. Since $\beta^{i}$ and $\lambda^{L, i}$ have a nonlinear relationship in the bond pricing formula to be detailed below, both are identified econometrically. The inclusion of the issuance date $t_{0}^{i}$ in the pricing formula captures the effect that, as time passes, an increasing fraction of a given security is held by buy-andhold investors. ${ }^{18}$ This limits the amount of the security available for trading and affects its sensitivity to the liquidity factor. Rational, forward-looking investors will take this dynamic

\footnotetext{
${ }^{17}$ AACMY and D'Amico et al. (2018) also allow for a single TIPS liquidity factor.

${ }^{18}$ Typically, primary dealers make the bulk of purchases of a security at issuance and little volume is locked up immediately. However, very close to when a bond matures, almost all remaining investors plan to hold the security to maturity.
} 
pattern into consideration when they determine what they are willing to pay for the security at any given point in time between the date of issuance and the maturity of the bond. This dynamic pattern is built into the model structure. In short, the measurement and identification of the TIPS liquidity pricing effects depend on the assumption that liquidity deteriorates over the lifetime of each bond (broadly consistent with Fontaine and Garcia, 2012). However, the individual form of that deterioration is determined by a very flexible structure that can vary substantially from bond to bond. Finally, we note that equation (6) can be combined with any dynamic term structure model to account for security-specific liquidity risks.

To augment the T-O model to account for the liquidity risk in the pricing of TIPS as described, let $X_{t}=\left(L_{t}, S_{t}, C_{t}, X_{t}^{l i q}\right)$ denote the state vector of the four-factor TIPS-only with liquidity adjustment (T-O-L) model. As in the non-augmented model, we let the frictionless instantaneous real risk-free rate be defined by equation (3), while the risk-neutral dynamics of the state variables used for pricing are given by

$$
\left(\begin{array}{c}
d L_{t} \\
d S_{t} \\
d C_{t} \\
d X_{t}^{l i q}
\end{array}\right)=\left(\begin{array}{cccc}
0 & 0 & 0 & 0 \\
0 & \lambda & -\lambda & 0 \\
0 & 0 & \lambda & 0 \\
0 & 0 & 0 & \kappa_{l i q}^{\mathbb{Q}}
\end{array}\right)\left[\left(\begin{array}{c}
0 \\
0 \\
0 \\
\theta_{l i q}^{\mathbb{Q}}
\end{array}\right)-\left(\begin{array}{c}
L_{t} \\
S_{t} \\
C_{t} \\
X_{t}^{l i q}
\end{array}\right)\right] d t+\Sigma\left(\begin{array}{c}
d W_{t}^{L, \mathbb{Q}} \\
d W_{t}^{S, \mathbb{Q}} \\
d W_{t}^{C, \mathbb{Q}} \\
d W_{t}^{l i q, \mathbb{Q}}
\end{array}\right),
$$

where $\Sigma$ continues to be a diagonal matrix.

It follows from these $\mathbb{Q}$-dynamics that TIPS yields are sensitive to liquidity risk. In particular, pricing of TIPS is not performed with the frictionless real discount function, but rather with the discount function that accounts for the liquidity risk as detailed earlier:

$$
\bar{r}_{t}^{i}=r_{t}+\beta^{i}\left(1-e^{-\lambda^{L, i}\left(t-t_{0}^{i}\right)}\right) X_{t}^{l i q}=L_{t}+S_{t}+\beta^{i}\left(1-e^{-\lambda^{L, i}\left(t-t_{0}^{i}\right)}\right) X_{t}^{l i q}
$$

In a supplementary appendix also available upon request, we show that the net present value of one unit of consumption paid by TIPS $i$ at time $t+\tau$ has the following exponential-affine form

$$
\begin{aligned}
P_{t}\left(t_{0}^{i}, \tau\right) & =E_{t}^{\mathbb{Q}}\left[e^{-\int_{t}^{t+\tau} \bar{r}^{i}\left(s, t_{0}^{i}\right) d s}\right] \\
& =\exp \left(B_{1}(\tau) L_{t}+B_{2}(\tau) S_{t}+B_{3}(\tau) C_{t}+B_{4}\left(t, t_{0}^{i}, \tau\right) X_{t}^{L i q}+A\left(t, t_{0}^{i}, \tau\right)\right)
\end{aligned}
$$

This result implies that the model belongs to the class of Gaussian affine term structure models, but unlike standard Gaussian models, $P_{t}\left(t_{0}^{i}, \tau^{i}\right)$ is not time homogeneous. Note also that, by fixing $\beta^{i}=0$ for all $i$, we recover the T-O model.

Now, consider the whole value of the TIPS $i$ issued at time $t_{0}^{i}$ with maturity at $t+\tau^{i}$ that 
pays an annual coupon $C^{i}$ semi-annually. At time $t$, this value is given by the sum of the next (prorated) coupon payment, subsequent coupons, and the principal-all appropriately discounted:

$$
\begin{aligned}
\bar{P}_{t}\left(t_{0}^{i}, \tau^{i}, C^{i}\right)= & C^{i}\left(t_{1}-t\right) E_{t}^{\mathbb{Q}}\left[e^{-\int_{t}^{t_{1}} \bar{r}^{R, i}\left(s, t_{0}^{i}\right) d s}\right]+\sum_{j=2}^{N} \frac{C^{i}}{2} E_{t}^{\mathbb{Q}}\left[e^{-\int_{t}^{t_{j}} \bar{r}^{R, i}\left(s, t_{0}^{i}\right) d s}\right] \\
& +E_{t}^{\mathbb{Q}}\left[e^{-\int_{t}^{t+\tau^{i}} \bar{r}^{R, i}\left(s, t_{0}^{i}\right) d s}\right] .
\end{aligned}
$$

Specifically, when a TIPS is purchased at time $t$, the investor pays for a prorated share of the next coupon payment, namely, the portion that has yet to accrue from $t$ to $t_{1}$. Subsequently, the investor receives $C^{i} / 2$ every six months as reflected in the price. The special treatment of the first coupon to be paid after time $t$ maps directly to our use of "clean" TIPS price data (unlike "dirty" bond prices that include accrued interest).

There are two minor omissions in this bond pricing formula. First, it does not account for the lag in the inflation indexation of the TIPS payoff. The potential error from this omission should be modest (see Grishchenko and Huang 2013), especially as we exclude bonds from our sample when they have less than one year remaining maturity. Second, our pricing neglects the potential deflation protection option in TIPS. TIPS offer some deflation projection because investors are guaranteed the return of their original principal even if the price index declines on net over the life of the bond. This deflation protection option is at the money for every TIPS upon issuance; however, with generally positive inflation since 1997, these options have quickly fallen deeply out of the money and have become of negligible value (see ACR for discussion).

Finally, to complete the description of the T-O-L model, we again specify an essentially affine risk premium structure, which implies that the risk premiums $\Gamma_{t}$ take the form

$$
\Gamma_{t}=\gamma^{0}+\gamma^{1} X_{t}
$$

where $\gamma^{0} \in \mathbf{R}^{4}$ and $\gamma^{1} \in \mathbf{R}^{4 \times 4}$ contain unrestricted parameters. Thus, the resulting unrestricted four-factor T-O-L model has $\mathbb{P}$-dynamics given by

$$
\left(\begin{array}{c}
d L_{t} \\
d S_{t} \\
d C_{t} \\
d X_{t}^{l i q}
\end{array}\right)=\left(\begin{array}{cccc}
\kappa_{11}^{\mathbb{P}} & \kappa_{12}^{\mathbb{P}} & \kappa_{13}^{\mathbb{P}} & \kappa_{14}^{\mathbb{P}} \\
\kappa_{21}^{\mathbb{P}} & \kappa_{22}^{\mathbb{P}} & \kappa_{23}^{\mathbb{P}} & \kappa_{24}^{\mathbb{P}} \\
\kappa_{31}^{\mathbb{P}} & \kappa_{32}^{\mathbb{P}} & \kappa_{33}^{\mathbb{P}} & \kappa_{34}^{\mathbb{P}} \\
\kappa_{41}^{\mathbb{P}} & \kappa_{42}^{\mathbb{P}} & \kappa_{43}^{\mathbb{P}} & \kappa_{44}^{\mathbb{P}}
\end{array}\right)\left(\left(\begin{array}{c}
\theta_{1}^{\mathbb{P}} \\
\theta_{2}^{\mathbb{P}} \\
\theta_{3}^{\mathbb{P}} \\
\theta_{4}^{\mathbb{P}}
\end{array}\right)-\left(\begin{array}{c}
L_{t} \\
S_{t} \\
C_{t} \\
X_{t}^{l i q}
\end{array}\right)\right) d t+\Sigma\left(\begin{array}{c}
d W_{t}^{L, \mathbb{P}} \\
d W_{t}^{S, \mathbb{P}} \\
d W_{t}^{C, \mathbb{P}} \\
d W_{t}^{l i q, \mathbb{P}}
\end{array}\right)
$$

This is the transition equation in the Kalman filter estimation. We stress that this structure allows for full flexibility in the dynamic interactions between all four factors under the 


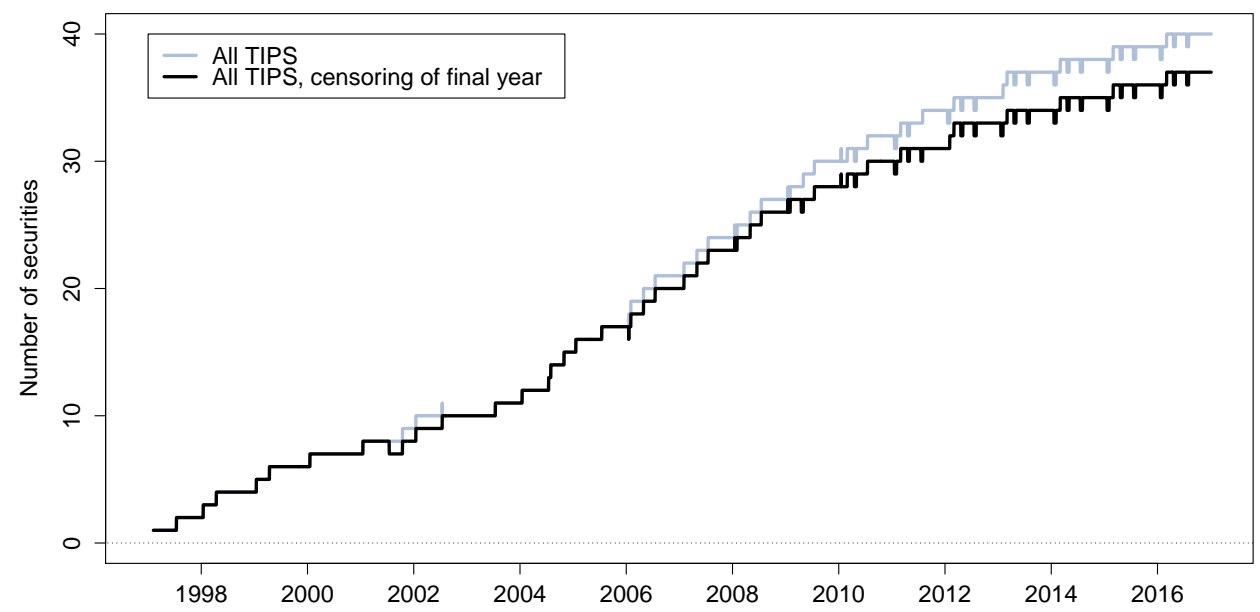

Figure 2: Number of TIPS Outstanding

objective $\mathbb{P}$-measure used in the definition of $r_{t}^{*}$.

\section{The TIPS Data}

The U.S. Treasury first issued inflation-indexed securities on February 6, 1997. At the end of our sample on December 30, 2016, the total amount of outstanding TIPS had a face value of $\$ 1.2$ trillion, which accounted for about 9 percent of all marketable Treasury debt. ${ }^{19}$ The total number of outstanding TIPS over time is shown as a solid gray line in Figure 2. At the end of our sample period - which runs from April 1998 to December 2016 - 40 TIPS were outstanding. However, as noted by Gürkaynak et al. (2010) and ACR, prices of TIPS near their maturity tend to be somewhat erratic because of the indexation lag in TIPS payouts. Therefore, to facilitate model estimation, we censor TIPS from our sample when they have less than one year to maturity. Using this cutoff, the number of TIPS in the sample is modestly reduced as shown with a solid black line in Figure 2.

The U.S. Treasury has issued ten-year TIPS on a regular basis and five-, twenty-, and thirty-year TIPS more sporadically. The maturity distribution of all 62 TIPS that have been issued since the inception of the indexed-debt program through the end of 2016 is shown in Figure 3. Each TIPS that has been issued is represented by a single downward-sloping line that plots its remaining years to maturity for each date. For the 5- to 10-year maturities of particular interest for our analysis, the universe of TIPS provides fairly good coverage.

\footnotetext{
${ }^{19}$ The data are available at: http://www.treasurydirect.gov/govt/reports/pd/mspd/2016/opds122016.pdf
} 


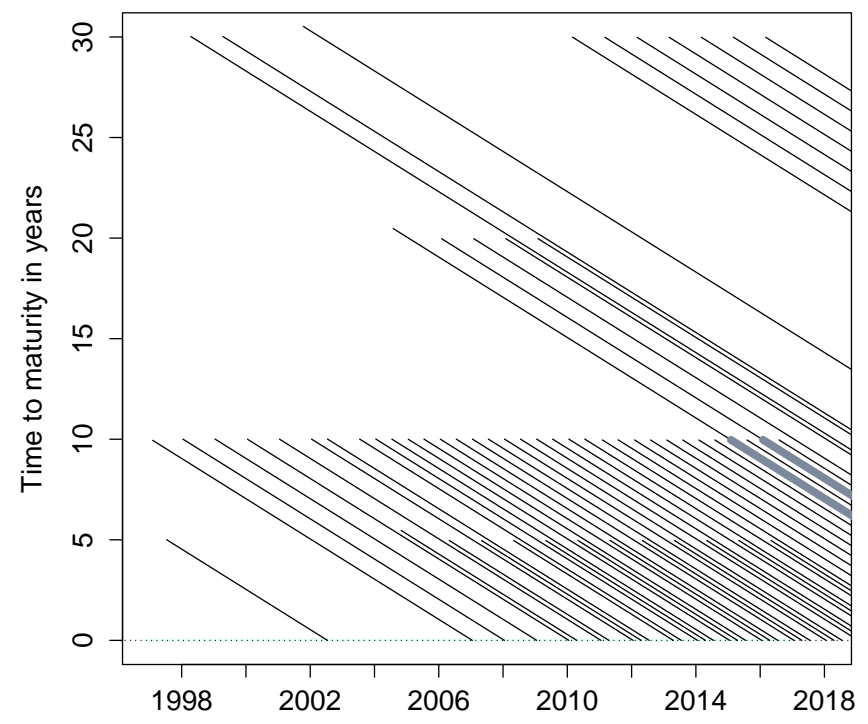

Figure 3: Maturity Distribution of all TIPS Issued

The maturity distribution of all TIPS issued is shown by solid black lines. Thick red lines highlight overlapping pairs of recent ten-year and seasoned twenty-year TIPS with identical maturity dates.

\section{Estimation of TIPS-only Term Structure Models}

In this section, we describe the restrictions imposed to achieve econometric identification of the real term structure models estimated using only TIPS. We then compare estimates of models with and without a liquidity adjustment.

\subsection{Econometric Identification}

Due to the nonlinearity of the TIPS pricing formula, the models cannot be estimated with the standard Kalman filter. Instead, we use the extended Kalman filter as in Kim and Singleton (2012), see the appendix available upon request for details. To make the fitted errors comparable across TIPS of different maturities, we scale each TIPS price by its duration. Thus, the measurement equation for the TIPS prices takes the following form:

$$
\frac{\bar{P}_{t}\left(t_{0}^{i}, \tau^{i}, C^{i}\right)}{D_{t}\left(\tau^{i}, C^{i}\right)}=\frac{\widehat{P}_{t}\left(t_{0}^{i}, \tau^{i}, C^{i}\right)}{D_{t}\left(\tau^{i}, C^{i}\right)}+\varepsilon_{t}^{i}
$$

where $\widehat{P}_{t}\left(t_{0}^{i}, \tau^{i}, C^{i}\right)$ is the model-implied price of TIPS $i$ and $D_{t}\left(\tau^{i}, C^{i}\right)$ is its duration, which is fixed and calculated before estimation. We assume that all TIPS measurement errors are normal i.i.d. with zero mean and standard deviation $\sigma_{\varepsilon}$. Andreasen et al. (2019) provide 


\begin{tabular}{|c|ccc||c||c|c|}
\hline$K^{\mathbb{P}}$ & $K_{\cdot, 1}^{\mathbb{P}}$ & $K_{\cdot, 2}^{\mathbb{P}}$ & $K_{\cdot, 3}^{\mathbb{P}}$ & $\theta^{\mathbb{P}}$ & & $\Sigma$ \\
\hline$K_{1, \cdot}^{\mathbb{P}}$ & 0.2163 & -0.0671 & -0.0500 & 0.0349 & $\sigma_{11}$ & 0.0045 \\
& $(0.1642)$ & $(0.0539)$ & $(0.0496)$ & $(0.0082)$ & & $(0.0001)$ \\
$K_{2, \cdot}^{\mathbb{P}}$ & -0.1839 & 0.9019 & -0.0561 & -0.0236 & $\sigma_{22}$ & 0.0247 \\
& $(1.0284)$ & $(0.3836)$ & $(0.4015)$ & $(0.0076)$ & & $(0.0010)$ \\
$K_{3, \cdot}^{\mathbb{P}}$ & -1.7790 & 0.4520 & 1.0854 & -0.0183 & $\sigma_{33}$ & 0.0281 \\
& $(1.1688)$ & $(0.4941)$ & $(0.4772)$ & $(0.0162)$ & & $(0.0018)$ \\
\hline
\end{tabular}

Table 1: Estimates of T-O Model

The table shows the estimated parameters of the $K^{\mathbb{P}}$ matrix, $\theta^{\mathbb{P}}$ vector, and diagonal $\Sigma$ matrix in the T-O model. The estimated value of $\lambda$ is 0.3849 (0.0032). The maximum log likelihood value is 25,852.69. The numbers in parentheses are the estimated parameter standard deviations.

extensive discussion and support for this specification of the measurement equation.

Initial identification of the four factors of the T-O-L model requires at least four TIPS securities, so the earliest starting date for model estimation is with the issuance of the fourth TIPS in April 1998. ${ }^{20}$ Since the liquidity factor is latent, its level is not identified without additional restrictions. As a consequence, we let the first thirty-year TIPS issued, that is, the TIPS with 3.625\% coupon issued on April 15, 1998 with maturity on April 15, 2028, have a unit loading on the liquidity factor, that is, $\beta^{i}=1$ for this security. This choice implies that the $\beta^{i}$ sensitivity parameters measure liquidity sensitivity relative to that of the thirty-year 2028 TIPS, but this choice has no implications for the level of $r_{t}^{*}$.

Furthermore, we note that the $\lambda^{L, i}$ parameters can be hard to identify if their values are too large or too small. Therefore, we impose the restriction that they fall within the range from 0.0001 to 10 . Although binding for a few TIPS, these restrictions are effectively without any practical consequences. Also, for numerical stability during model optimization, we impose the restriction that the $\beta^{i}$ parameters fall within the range from 0 to 250 , which also turns out not to be a binding constraint at the optimum. ${ }^{21}$

\subsection{Model Estimates}

Comparing the estimated real term structure T-O and T-O-L models can elucidate their differing dynamics and the effect of the liquidity adjustment. The estimated dynamic parameters of these models are reported in Tables 1 and 2. In both models, the usual pattern holds that the level factor is the most persistent and least volatile factor, while the slope and curvature factor are less persistent and much more volatile. Also, both estimates of $\lambda$ are about 0.4 , which is typical of previous estimates for this parameter using nominal U.S.

\footnotetext{
${ }^{20}$ Identification of the T-O model requires only three TIPS, so its estimation sample starts in January 1998.

${ }^{21}$ As documented by Christensen et al. (2017), on-the-run premiums in the TIPS market appear minimal unlike in the regular Treasury market. By implication, there are no special price dynamics for individual TIPS following their issuance to take into account.
} 


\begin{tabular}{|c|cccc||c||c|c|}
\hline$K^{\mathbb{P}}$ & $K_{\cdot, 1}^{\mathbb{P}}$ & $K_{\cdot, 2}^{\mathbb{P}}$ & $K_{\cdot, 3}^{\mathbb{P}}$ & $K_{\cdot, 4}^{\mathbb{P}}$ & $\theta^{\mathbb{P}}$ & & $\Sigma$ \\
\hline$K_{1, \cdot}^{\mathbb{P}}$ & 0.4200 & 0.0079 & -0.0361 & 0.2901 & 0.0369 & $\sigma_{11}$ & 0.0053 \\
& $(0.2860)$ & $(0.1112)$ & $(0.0850)$ & $(0.2529)$ & $(0.0136)$ & & $(0.0003)$ \\
$K_{2, \cdot}^{\mathbb{P}}$ & 0.9204 & 1.1853 & -0.0653 & 2.4599 & -0.0178 & $\sigma_{22}$ & 0.0210 \\
& $(0.7894)$ & $(0.4612)$ & $(0.4112)$ & $(0.7317)$ & $(0.0257)$ & & $(0.0026)$ \\
$K_{3, \cdot}^{\mathbb{P}}$ & -1.0592 & 0.2050 & 0.8798 & -0.3331 & -0.0220 & $\sigma_{33}$ & 0.0265 \\
& $(0.7653)$ & $(0.4669)$ & $(0.4406)$ & $(0.7149)$ & $(0.0233)$ & & $(0.0027)$ \\
$K_{4, \cdot}^{\mathbb{P}}$ & 1.2109 & 0.3911 & -0.4036 & 1.7962 & -0.0036 & $\sigma_{44}$ & 0.0238 \\
& $(0.8638)$ & $(0.5426)$ & $(0.5572)$ & $(0.7388)$ & $(0.0158)$ & & $(0.0052)$ \\
\hline
\end{tabular}

Table 2: Estimates of the T-O-L Model

The table shows the estimated parameters of the $K^{\mathbb{P}}$ matrix, $\theta^{\mathbb{P}}$ vector, and diagonal $\Sigma$ matrix in the T-O-L model. The estimated value of $\lambda$ is $0.3902(0.0084)$, while $\kappa_{\text {liq }}^{\mathbb{Q}}=1.0457(0.0923)$ and $\theta_{\text {liq }}^{\mathbb{Q}}=$ 0.0018 (0.0004). The maximum log likelihood value is $28,581.82$. The numbers in parentheses are the estimated parameter standard deviations.

Treasury data. Thus, in terms of dynamic characteristics for the frictionless factors in the models, the results are very similar to what other studies have reported for nominal Treasury yields using standard Gaussian AFNS models.

The estimated paths of the level, slope, and curvature factors from the two models are shown in Figure 4. The two models' level and curvature factors are fairly close to each other during the entire sample, but there is a notable difference between the two estimated slope factors in the years following the financial crisis. Accordingly, the main impact of accounting for TIPS liquidity premiums is on the slope of the frictionless real yield curve. As we demonstrate later, this affects the models' longer-run projections of real rates and hence the estimates of the natural rate. The fourth factor in the T-O-L model, the liquidity factor, is a volatile but quickly mean-reverting process with an estimated mean of -0.0036 , which is only slightly below the average of its filtered path shown in Figure 4(d). The liquidity factor notably jumps during the 2008-2009 financial crisis, which is consistent with the extensive financial market dislocations of that period. It is also elevated during the first several years after the introduction of TIPS when there was some uncertainty about whether the U.S. Treasury was committed to continuing to issue TIPS on an ongoing basis. ${ }^{22}$

The estimated liquidity sensitivity parameters $\left(\beta^{i}, \lambda^{L, i}\right)$ for each TIPS in the sample are reported in the appendix available upon request. The estimated values of $\beta^{i}$ are mostly in the vicinity of one, but a fair number of TIPS have values much higher to offset the impact of very low values of $\lambda^{L, i}$, which creates a unique shape for their yield sensitivity to the liquidity

\footnotetext{
${ }^{22}$ TIPS liquidity premiums reflect expectations under the risk-neutral $\mathbb{Q}$-measure. Given its positive mean under that measure, even a negative value of the liquidity risk factor will not necessarily imply a negative liquidity premium for most of the TIPS in our sample. However, a negative liquidity premium is feasible in the model and occasionally occurs signalling a security so desirable that investors are willing to pay a premium to hold it.
} 


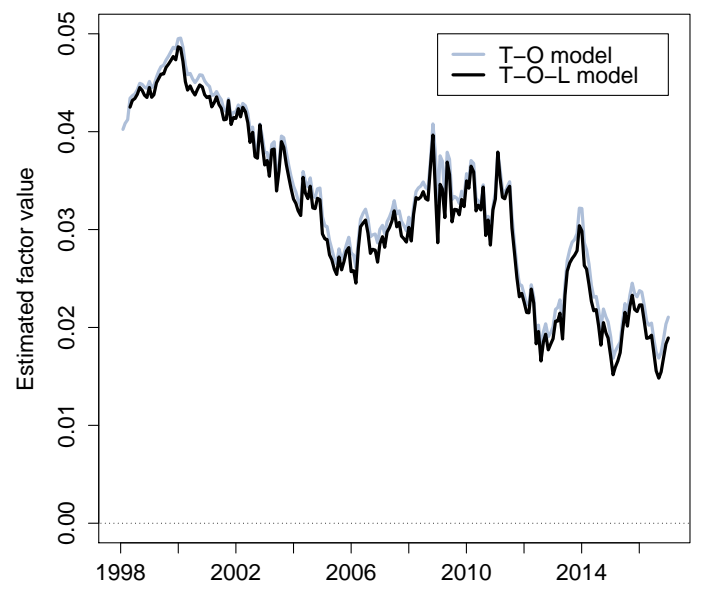

(a) $L_{t}$

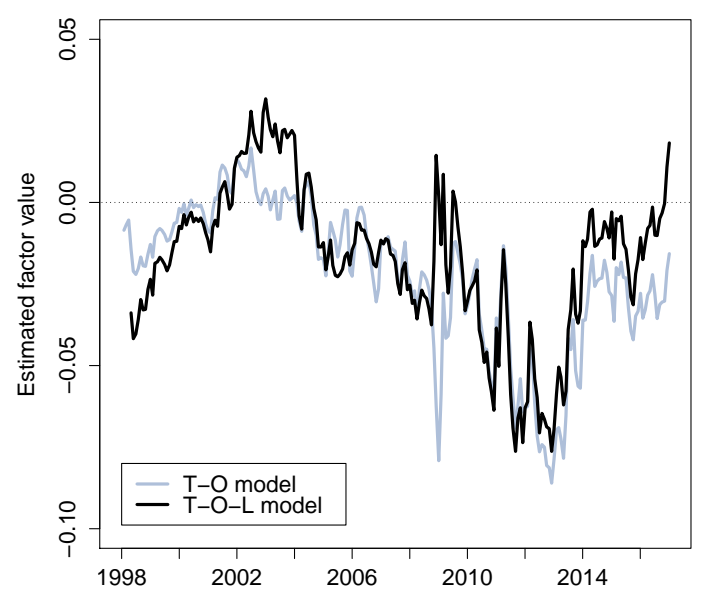

(c) $C_{t}$

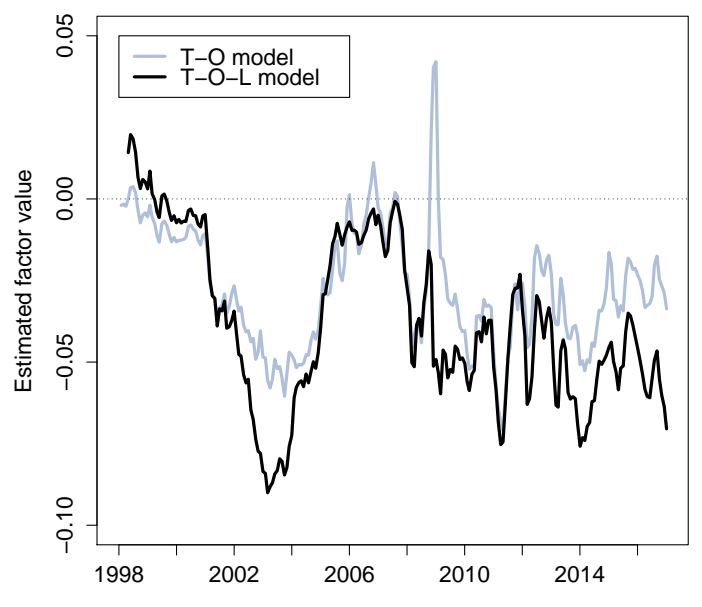

(b) $S_{t}$

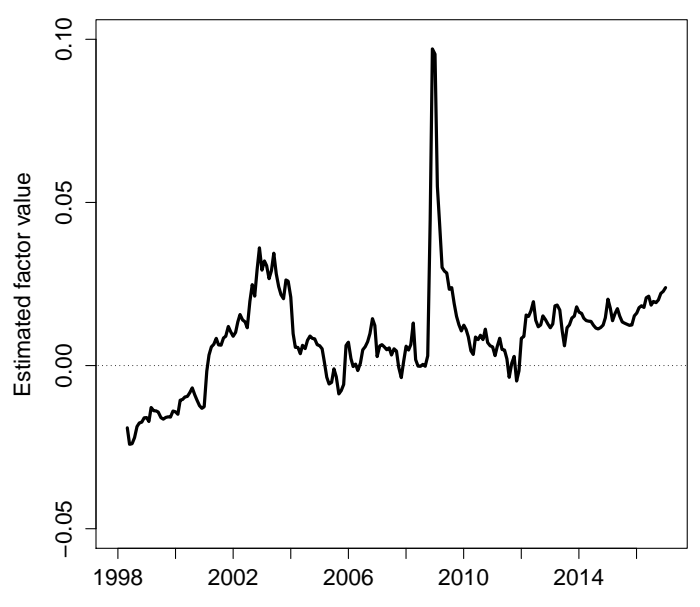

(d) $X_{t}^{l i q}$

Figure 4: Estimated State Variables

Illustration of the estimated state variables from the T-O and T-O-L models. The sample used in the T-O model estimation is monthly covering the period from January 1998 to December 2016, while the sample used in the T-O-L model estimation is monthly covering the period from April 1998 to December 2016.

risk factor as explained in ACR. The appendix also reports the summary statistics for the fitted errors of each TIPS implied by both the T-O model and the T-O-L model (which have 17 and 151 estimated parameters, respectively). These errors are calculated by converting the fitted TIPS prices from the model estimation into fitted yields to maturity that are deducted from the mid-market yields to maturity downloaded from Bloomberg. For all TIPS yields combined, the RMSE is 8.65 basis points for the T-O model and 4.34 basis points for the 


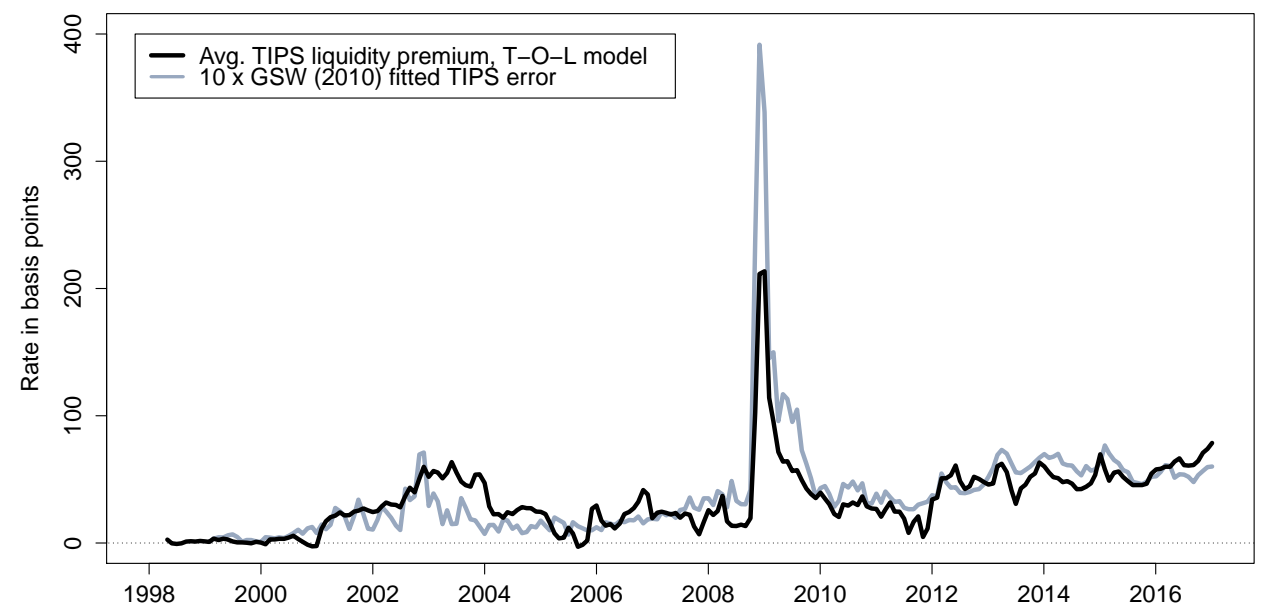

Figure 5: Measures of the TIPS Liquidity Premium

The average estimated TIPS liquidity premium across all TIPS available in each month as implied by the T-O-L model estimated with monthly data from April 1998 to December 2016. A TIPS liquidity premium is measured as the estimated yield difference between the fitted yield to the maturity of an individual TIPS and the corresponding frictionless yield to maturity with the liquidity risk components zeroed out. Also shown are the TIPS mean absolute fitting errors from Gürkaynak et al. (2010, henceforth GSW). This series represents deviations in the prices of TIPS from a fitted yield curve and has been scaled up by a factor of 10 for comparability.

T-O-L model. The T-O-L model fits about as well as in ACR, although they only use fiveand ten-year TIPS yields in their analysis, which suggests that - consistent with Andreasen et al. (2019) - there is no material loss in model performance from using all available TIPS bond price information rather than modeling just a few interpolated synthetic zero-coupon yields.

Figure 5 shows the estimated TIPS liquidity premium averaged across all available TIPS at each point in time. With the exception of the financial crisis, this average liquidity premium has been relatively stable over the sample. ${ }^{23}$ The relative stability of the liquidity premium implies that it does not account for the persistent downtrend in real yields. The mean of this average liquidity premium, which is 34 basis points, and the time series pattern of variation are similar to the estimate reported by ACR, although their data are weekly and for a shorter sample. Figure 5 also shows an average measure of fit to a smoothed yield curve of individual TIPS at each point in time as an observable proxy for liquidity. Specifically, this measure is the mean absolute deviation of all TIPS yield curve fitting errors following Gürkaynak

\footnotetext{
${ }^{23}$ Some of the increase in the average TIPS liquidity premium during our sample period reflects a lengthening of the average TIPS maturity over time.
} 
et al. (2010, henceforth GSW). This series represents the degree to which TIPS prices are outliers or unusually different from their near-maturity neighbors at any point in time. Hu et al. (2013) argue that such deviations measure time variation in the availability of arbitrage capital and therefore constitute useful proxies for illiquidity. This fitted-error variable is highly positively correlated $(87 \%)$ with our estimated average TIPS liquidity premium series, which supports our liquidity premium estimates. Further analysis of the estimated liquidity premiums is provided in the appendix available upon request.

In the asset pricing literature, there is much debate about the shape of the real yield curve. Here, we model observed TIPS prices directly with a flexible T-O-L model structure that accommodates level, slope, and curvature patterns in the frictionless part of the TIPS data. Hence, our analysis is imposing a minimum of restrictions on the fundamental or frictionless real yield curve. Yet the empirical results reveal that, for U.S. data, it is indeed the case that the frictionless real yield curve is upward sloping most of the time as also suggested by the observable TIPS yields. This can also be inferred from Figures 4(b) and 4(c) by the fact that the slope and curvature factor within the T-O-L model are generally negative.

\section{A Lower New Normal for Interest Rates?}

In this section, we use TIPS-only models to obtain expected real short rates and the associated measure of the equilibrium real rate. We then compare this estimate to other market-based and macro-based estimates from the literature and consider the persistence of forces that may be pushing the real rate lower.

\subsection{TIPS-only Estimates of the Natural Rate}

Our finance- or market-based measure of the natural rate is the average expected real short rate over a five-year period starting five years ahead. This 5yr5yr forward average expected real short rate should be little affected by short-term transitory shocks and well positioned to capture the persistent trends in the natural real rate. Figure 6 compares the estimates of $r_{t}^{*}$ from the T-O-L and T-O models, that is, with and without an explicit adjustment for timevarying liquidity effects in TIPS prices. Accounting for the liquidity premiums in the T-O-L model leads to some differences, with the T-O-L model $r_{t}^{*}$ displaying more cyclical variation in the first half of the sample. In addition, the T-O-L model estimate has notable volatility during the financial crisis. Still, the general magnitude and timing of the overall downtrend in the estimates of the equilibrium interest rate are similar across the two specifications. The estimates gradually decline from around 2 to 3 percent in 2000 to near zero by the 


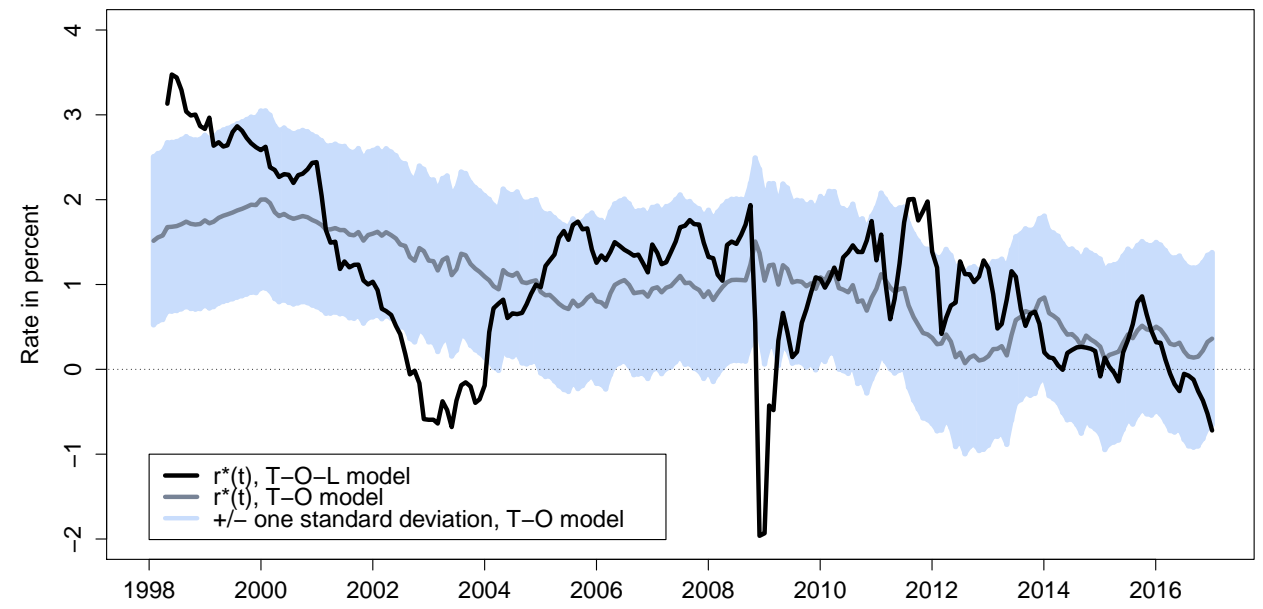

Figure 6: Comparison of $\mathbf{r}^{*}$ Estimates from T-O and T-O-L Models

end of the sample. ${ }^{24}$ Figure 6 also provides evidence regarding the statistical significance of the $r_{t}^{*}$ estimates by including a confidence interval for the T-O model estimate based on a Monte Carlo analysis. ${ }^{25}$ These simulation-based confidence intervals indicate considerable uncertainty, with a one standard deviation of the $r_{t}^{*}$ estimate of roughly one percentage point. ${ }^{26}$ Clearly, there is no statistical basis to differentiate between the two estimates, and for robustness, we will focus on the average of the T-O and T-O-L model $r_{t}^{*}$ estimates for our analysis below. As noted above, each specification has pros and cons: the T-O model is a parsimonious representation, while the T-O-L model is a highly parameterized specification that can provide sharper inference - if the underlying assumed structure is appropriate. Below we simply average the two estimates for a composite measure that smoothes out some of the model idiosyncracies. In the appendix available upon request, we further explore the robustness of the $r_{t}^{*}$ estimates to the choice of dynamic specification and the censoring of the challenging period around the peak of the financial crisis.

As noted in the introduction, real-time macro-based estimates of $r_{t}^{*}$ can be quite different from later estimates that look back in time. Finance-based estimates should be less subject to

\footnotetext{
${ }^{24}$ At face value, the occasional negative values of the T-O-L model estimate of the natural rate may seem unusual. Such values could result from short-run imbalances between global savings and available safe investment opportunities. Of course, given the uncertainty surrounding these estimates, one cannot rule out that $r_{t}^{*}$ has remained positive throughout our sample period.

${ }^{25}$ As detailed in the appendix available upon request, to construct these confidence intervals, we used the T-O model estimates to simulate data samples for the three state variables, converted these to bond price samples, added measurement error, and re-estimated the T-O model and associated $r_{t}^{*}$ path for each sample. Such a Monte Carlo exercise is not feasible for the T-O-L model due to the large number of parameters.

${ }^{26}$ This range of uncertainty is not necessarily lower than that surrounding the macro-based estimates. However, the two very different approaches - macro and finance - likely have largely orthogonal confidence intervals.
} 


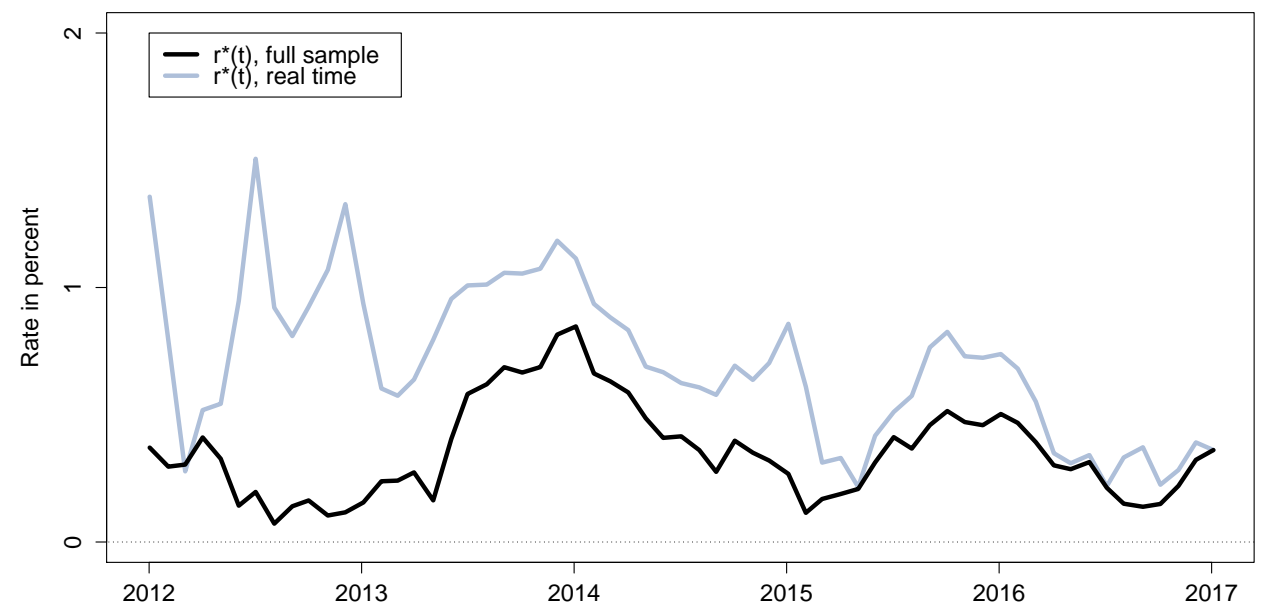

Figure 7: Accuracy of Real-Time Estimates of $\mathbf{r}^{*}$ in T-O Model

this criticism as they are based on data, namely the observed bond prices, that are available in real time and never revised. However, finance-based $r_{t}^{*}$ estimates could still be subject to revision as the model parameter estimates vary as the sample increases. To evaluate such concerns, we repeatedly estimate the T-O model with varying sample endpoints from January 2012 through December 2016 - a computationally difficult exercise for the T-O-L model. Figure 7 compares these expanding-sample estimates, which are effectively equivalent to real-time estimates of $r_{t}^{*}$, to the corresponding full-sample, "look-back" estimates. The average difference between these real-time and full-sample estimates is 0.35 percentage point, so that in real time, the equilibrium rate would have been estimated to be a bit higher than what the data at the end of 2016 indicate. Going forward, with a larger historical estimation sample, we would expect smaller revisions between real-time and final estimates.

Finally, estimates of the term premium from the T-O and T-O-L models provide another dimension for model comparison. Figure 8 shows the 5yr5yr real term premium estimates from each model and a confidence interval for the T-O model estimate based on the same Monte Carlo analysis described above. The real term premium estimates from the two models show little if any downtrend and broadly similar countercyclical dynamics - although the TO-L model displays somewhat greater volatility. The elevated level of the forward real term premium during economic recessions is consistent with theory. The very low estimated risk premia after 2010 may reflect the increase in TIPS purchases by the Federal Reserve as part of its large-scale asset purchases (or quantitative easing), which started in November 2010, see Christensen and Gillan (2018) for details. Again, the estimates from the two models are not 


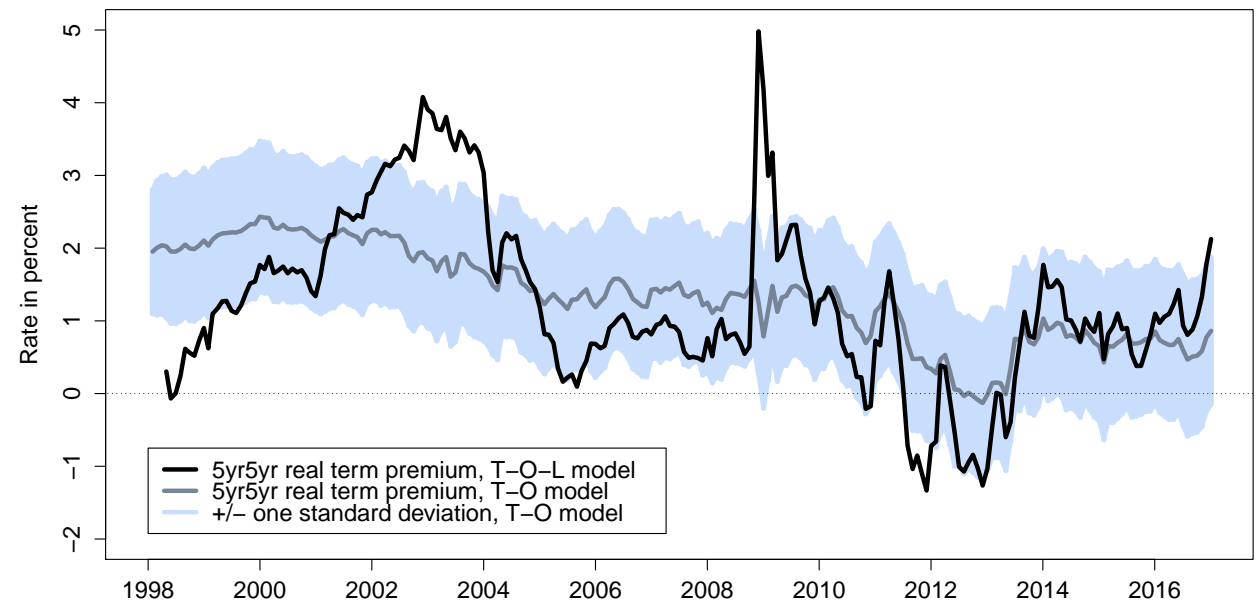

Figure 8: Comparison of Estimated Risk Premia from T-O and T-O-L Models

different from each other at conventional significance levels, and for our comparisons below, we will focus on their average risk premium estimate.

\subsection{Comparison with Other Estimates of the Natural Rate}

There are several other estimates of the equilibrium or natural interest rate in the literature to compare with our TIPS-only estimates. To start, we consider two other estimates that are also based on only financial models and bond market data. Specifically, we consider the joint models of nominal and real yields developed by AACMY and ACR, which also adjust for term and liquidity premiums in TIPS yields. All three market-based estimates of $r_{t}^{*}$ are shown in Figure 9. ${ }^{27}$ The ACR model is a five-factor structure that imposes restrictions between the slope and curvature of the nominal yield curve and those of the real yield curve that were first detailed in Christensen et al. (2010). The ACR model provides $r_{t}^{*}$ estimates that are slightly lower on average and more cyclically variable than our composite $\mathrm{CR} r_{t}^{*}$ estimate. By contrast, the AACMY model has a negative $r_{t}^{*}$ estimate for almost the entire sample, which is at odds with other estimates. AACMY use a very flexible six-factor model of nominal and real yields with two separate TIPS-specific factors, which provides very tight in-sample fit to the observed yields but potentially less accurate estimates of the factor $\mathbb{P}$-dynamics. Since those dynamics are critical to the model-implied estimates of $r_{t}^{*}$, as evident in equation (1),

\footnotetext{
${ }^{27}$ A very different perspective is provided by Kaminska and Zinna (2014), who estimate a no-arbitrage model of TIPS using official foreign and Fed bond demand as a pricing factor. They find steep cyclically-insensitive declines over the past two decades in the long-run real term premium - from 2 to -2 percent - and relatively stable expected future short rates.
} 


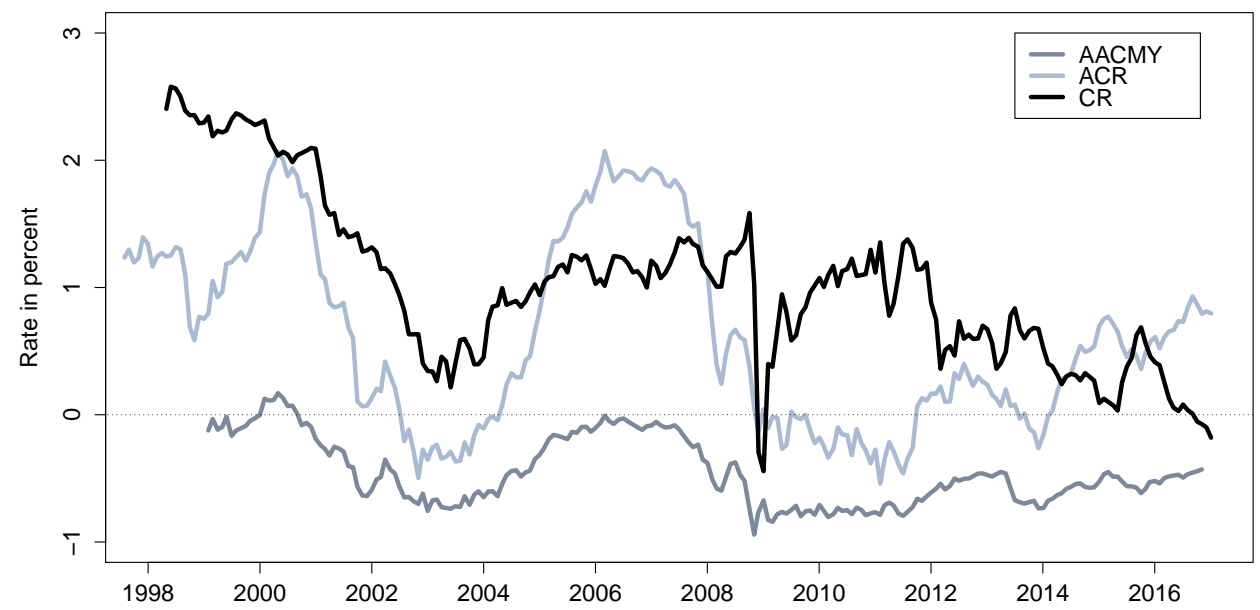

Figure 9: Comparison with Two Other Market-Based Estimates of $\mathbf{r}^{*}$ The CR estimate is the average of the T-O and T-O-L model estimates.

this may explain the unusually low AACMY estimates of $r_{t}^{*}$.

The associated estimates of the term premium from these arbitrage-free models provide another dimension for comparison. Figure 10 shows the 5yr5yr real term premium estimates from AACMY, ACR, and our CR estimate (the average of the T-O-L and T-O models). The $\mathrm{CR}$ and ACR real term premium estimates show similar countercyclical fluctuations. The CR estimate has little if any downward trend while the ACR estimate has only slightly more. The real term premium estimate from AACMY drifts notably lower over the sample, which could reflect insufficiently persistent factor dynamics from finite-sample bias as discussed in Bauer et al. (2012).

Now we turn to the crucial comparison of our finance-based estimate of $r_{t}^{*}$ with the estimates based on macroeconomic models and data. Figure 11 shows the CR average $r_{t}^{*}$ estimate together with a composite macro-based measure of $r^{*}$. The specific macro-based series shown - the grey line - is a summary measure that averages across three fairly similar macro-based estimates. ${ }^{28}$ The black line shows our TIPS-only estimate of $r_{t}^{*}$-an average of the T-O and T-O-L models. The macro-based estimate shown in the figure starts in 1980almost 20 years earlier than the start of the TIPS sample. However, in the 1980s and 1990s, the macro-based estimate changed little and generally remained between 2 and 2-1/2 percent. This is consistent with the received wisdom of that era in monetary economics that viewed

\footnotetext{
${ }^{28}$ Specifically, the macro-based composite is the average of the filtered estimate from Laubach and Williams (2016), the filtered mean estimate from Johannsen and Mertens (2016), and the estimated median from Lubick and Matthes (2015). The averaging smooths across the specific modeling assumptions underlying the different empirical representations in these studies. These estimates were obtained as of September 2018.
} 


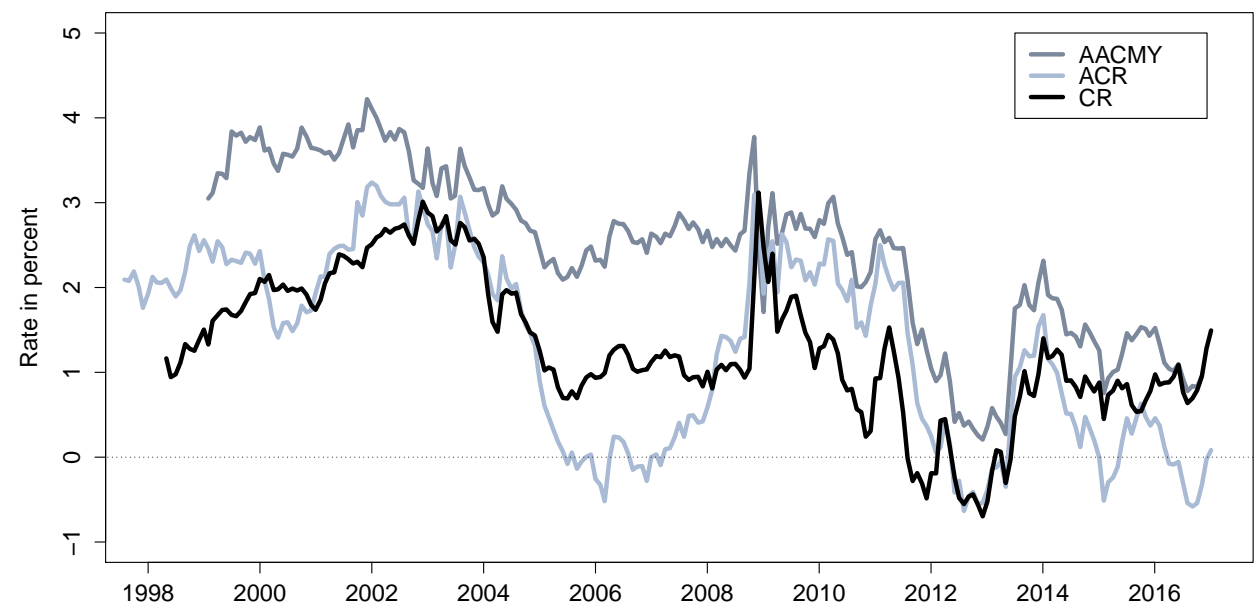

Figure 10: Estimates of the 5yr5yr Real Yield Term Premium

The CR estimate is the average of the T-O and T-O-L model estimates.

the natural rate as effectively constant-for example, as assumed in the large Taylor rule literature. It is only just after 2000 that a decided downtrend begins in the macro-based $r_{t}^{*}$ measure. This decline started shortly after the introduction of TIPS, which is a fortuitous coincidence of timing for our investigation. Accordingly, even though our estimation sample is limited to the past two decades, the evidence suggests that this is the very sample of most relevance for discerning shifts in the equilibrium real rate.

During their shared sample, the macro- and finance-based estimates exhibit a similar general trend - starting from just above 2 percent in the late 1990s and ending the sample near zero - and tell a similar story despite the differences in their volatility. ${ }^{29}$ Importantly, in terms of the levels of the natural rate estimates, both methodologies imply that $r_{t}^{*}$ is currently near its historical low. However, it should be noted that the TIPS-based natural rate estimates use the CPI as the price index, and the macro-based estimates use an alternative price deflator for personal consumption expenditures (PCEPI). Due to technical differences in construction and coverage, the PCEPI, on average, reports a bit lower inflation than the CPI. One forward-looking measure of this discrepancy is the difference between the 10-year-ahead forecasts for PCEPI and CPI inflation reported by the Survey of Professional Forecasters. Over the sample from 2007:Q1 to 2017:Q1, the average difference between these two forecasts is 23 basis points. Therefore, on PCEPI basis, our finance-based estimate of the $r_{t}^{*}$ would be

\footnotetext{
${ }^{29}$ Our finance-based measures of $r_{t}^{*}$ tend to be more volatile, partly because they are observed at a higher frequency. Furthermore, the relative volatility of financial asset prices compared with apparent fundamentals has long been noted in a variety of contexts.
} 


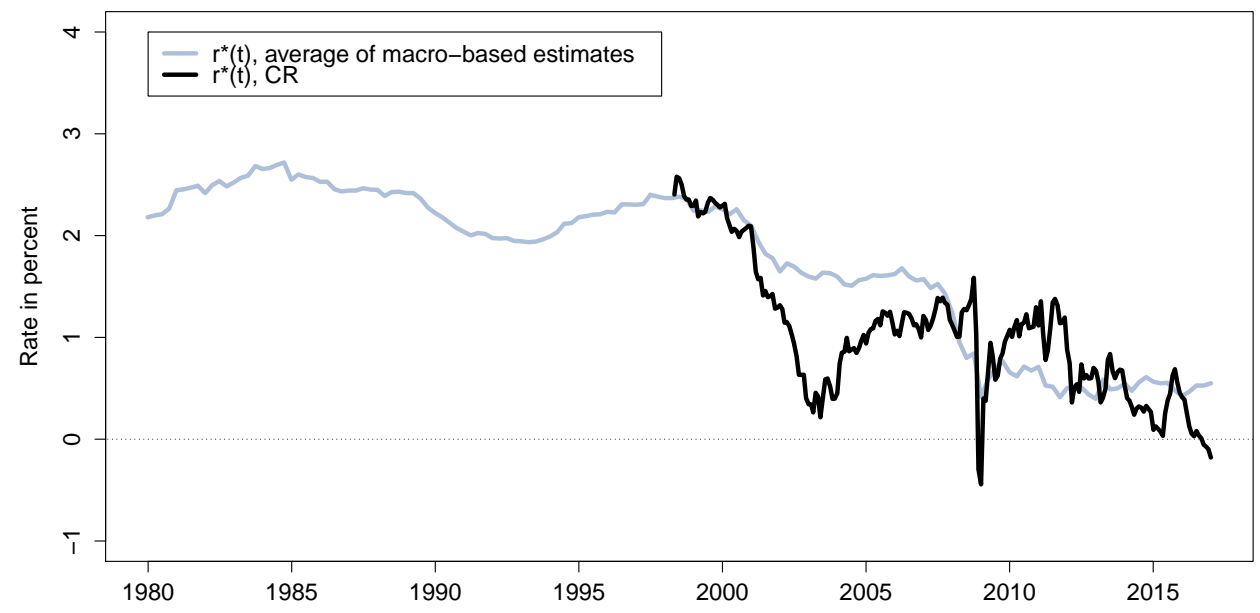

Figure 11: Comparison with Macro-Based Estimates of $\mathbf{r}^{*}$

The CR estimate is the average of the T-O and T-O-L model estimates.

modestly higher - by about a quarter percentage point - than the version shown in Figure 11.

There are also differences between the two estimates with regards to the timing of the decline in $r_{t}^{*}$. The macro-based estimate of the natural rate shows a fairly modest decline from the late 1990s until the financial crisis and the start of the Great Recession. Then, it drops precipitously to less than 1 percent and edges only slightly lower thereafter. Arguably, this path leaves open the possibility that the Great Recession and the associated financial crisis played a key role in the decline in $r_{t}^{*}$ during the past decade. Such an interpretation suggests that the drop in $r_{t}^{*}$ could be at least partly reversed by a cyclical boom. In contrast, the drop in the finance-based $r_{t}^{*}$ estimate does not coincide with the Great Recession. The TIPS-only estimate instead declines in the early 2000s, stabilizes, and then declines a bit more starting in 2012. Therefore, the finance-based version suggests that the path of the equilibrium rate has secular, more persistent drivers.

Finally, Figure 12 compares our CR $r_{t}^{*}$ to estimates of the natural real rate implied in the long-run forecasts from the Blue Chip Financial Forecasts survey of professional forecasters and from the Congressional Budget Office (CBO). The Blue Chip and CBO natural rate estimates are obtained by subtracting 5- to 10-year ahead projected CPI inflation from the projected three-month Treasury bill rate at a similar horizon, as in Leduc and Rudebusch (2014). Note that our finance-based $r_{t}^{*}$ estimate is highly positively correlated with the $r_{t}^{*}$ estimate implied by the Blue Chip survey with the same notable decline in the early 2000s. The CBO's estimate changes little for much of the early sample, but like the other $r_{t}^{*}$ series, it also exhibits a clear downtrend later on. 


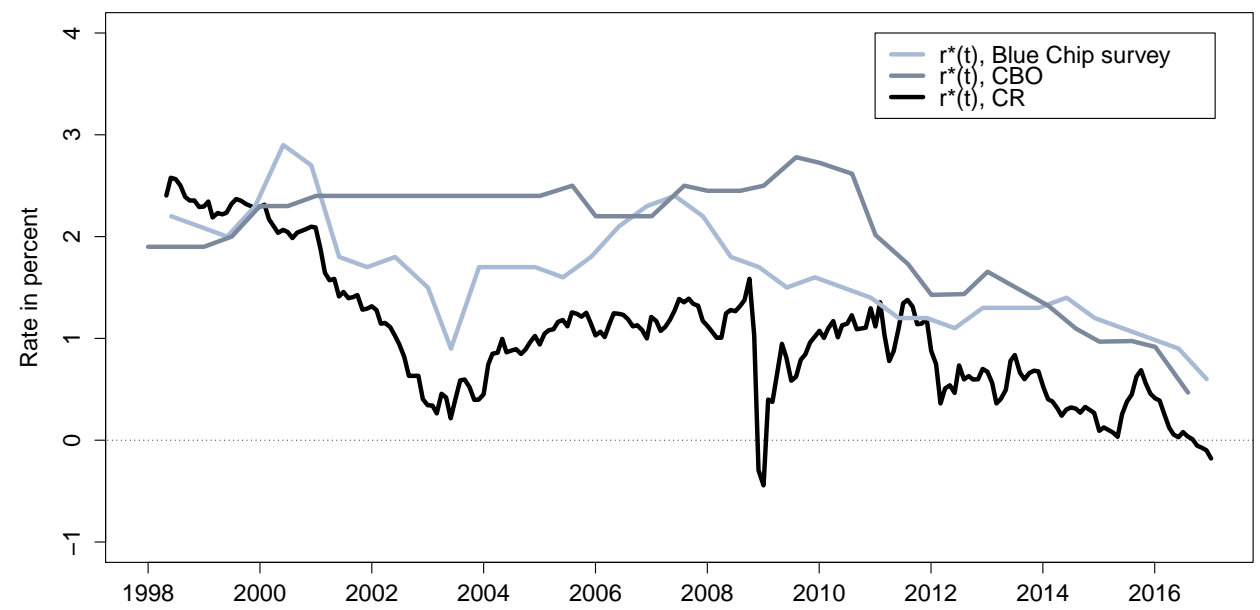

Figure 12: Comparison with Blue Chip and CBO Estimates of $\mathbf{r}^{*}$

The CR estimate is the average of the T-O and T-O-L model estimates.

\subsection{Whither the Natural Rate?}

In light of the intense debate among researchers, investors, and policymakers about a possible lower new normal for interest rates, we end our analysis by presenting the outlook for the natural rate based on estimated model projections as well as discussing some of the potential drivers of a lower real rate. We follow the approach of Christensen et al. (2015) and simulate 10,000 factor paths over a ten-year horizon conditioned on the shape of the TIPS yield curve and investors' embedded forward-looking expectations as of the end of our sample (that is, using estimated state variables and factor dynamics as of December 30, 2016). The simulated factor paths are then converted into forecasts of $r_{t}^{*}$. This simulation procedure is only feasible for the T-O model, so we limit this analysis to that model. Figure 13 shows the median projection and the 5th and 95th percentile values for the simulated natural rate over a tenyear forecast horizon. ${ }^{30}$

The median $r_{t}^{*}$ projection shows only a very gradual partial reversal of the declines the past two decades and only reaches 1 percent after 2025. The upper 95th percentile rises more rapidly while the lower 5 th percentile represents outcomes with the natural rate remaining near zero over the entire forecast horizon. The underlying stationarity of the T-O model is clear in these conditional forecasts. In addition, like most estimates of persistent dynamics, the model will likely suffer from some finite-sample bias in the estimated parameters of its meanreversion matrix $K^{\mathbb{P}}$, which would imply that it does not exhibit sufficient persistence - as

\footnotetext{
${ }^{30}$ Note that the lines do not represent short rate paths from a single simulation run over the forecast horizon; instead, they delineate the distribution of all simulation outcomes at a given point in time.
} 


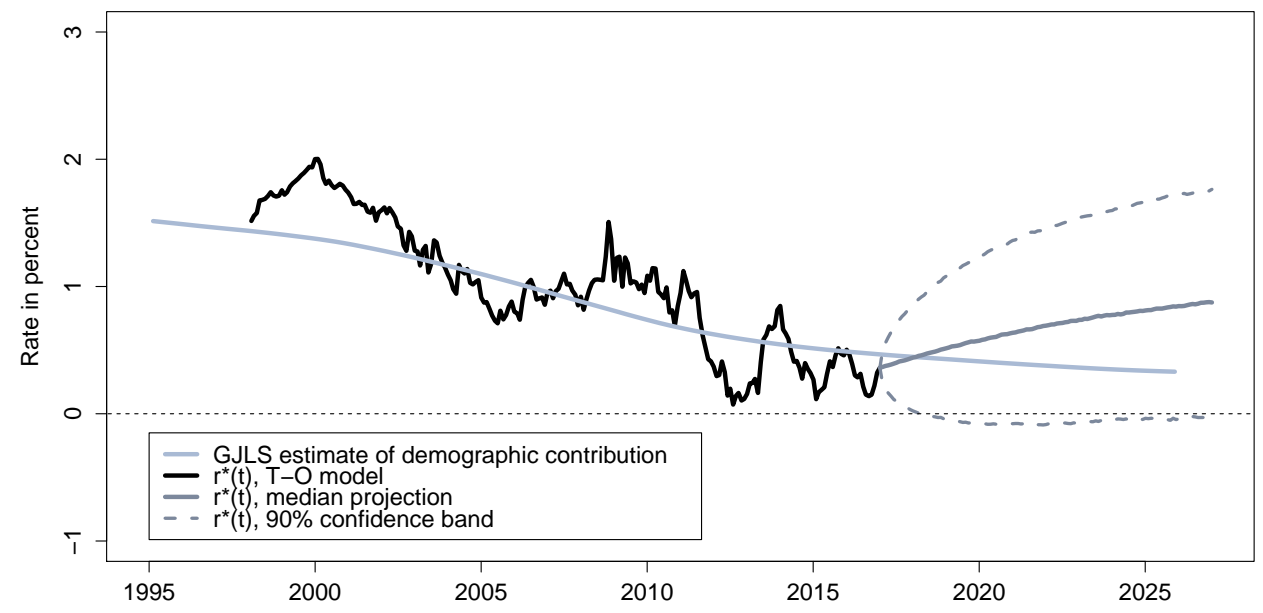

Figure 13: Ten-Year Projections of $\mathbf{r}^{*}$ from T-O Model

discussed in Bauer et al. (2012). In turn, this would suggest (all else equal) that the outcomes below the median are more likely than a straight read of the simulated probabilities indicate and, correspondingly, those above the median are less likely than indicated. As a consequence, we view the T-O model projections in Figure 13 to be closer to an upper bound on the true probability distribution of the future path for the natural rate. Therefore, it seems even more likely that the natural rate will remain below 1 percent for some time.

Although our analysis has focused on measuring the dynamic path of the equilibrium real rate, it is also of interest to relate these dynamics to macroeconomic developments. In particular, the past and future path of our TIPS-based estimate of $r_{t}^{*}$ is relevant to the debate about the source of the decline in the equilibrium real rate. Although our measure of the real rate fluctuated at the start of the global financial crisis, our average $r_{t}^{*}$ estimate in 2010 is not much different than in 2007. This relative stability before and after the Financial Crisis suggests that flight-to-safety and safety premium explanations of the lower equilibrium real rate are unlikely to be key drivers of the downtrend in Treasury rates (as proposed by Hall, 2016, and Del Negro et al., 2017, among others). Instead, our estimates appear more broadly consistent with many of the explanations that attribute the decline in the natural rate to real-side fundamentals.

To shed some light on these potential macroeconomic drivers, we first consider the connection between economic growth projections and bond market participants' perceptions of the equilibrium rate. Based on standard economic theories, such as the intertemporal consumption Euler equation, which connects the short real rate to consumption growth, longer-run 
economic growth is widely viewed as a key driver of the equilibrium rate. For example, this connection is integral to the Laubach and Williams $(2003,2016)$ analysis. To examine this relationship with our $r_{t}^{*}$ estimate, we regress monthly changes in $r_{t}^{*}$ on monthly revisions to the growth projections of private forecasters:

$$
\Delta r_{t}^{*}=\underset{(0.98)}{-1.16}+\underset{(0.04)}{0.24} \Delta g_{t}^{B C}+\varepsilon_{t}, \quad n_{o b s}=224, \quad R^{2}=0.14
$$

where $g_{t}^{B C}$ is the forecast for real gross domestic product (GDP) growth over the next four quarters from the Blue Chip Economic Indicator's monthly survey of business economists (and both series are measured in percentage points). This regression suggests that a 1 percentage point increase (decrease) in the four-quarter ahead GDP forecast tends to be associated with a 0.24 percentage point increase (decrease) in $r_{t}^{*}$. 31 This result is also statistically significant (standard errors are given below each coefficient in parentheses). In direction, the evidence is consistent with the theoretical benchmark connecting growth and real rates with a positive sign. In terms of magnitude, the slope coefficient is much less than the usual estimate of unity employed in, for example, Laubach and Williams (2003, 2016) and Fisher (2016). However, the monthly private-sector real GDP forecasts that are available are not for projections of longer-run trend or potential growth but are for growth over the next four quarters, which would certainly be more variable and require a smaller coefficient. A more serious caveat is that the results are largely driven by the observations during the Great Recession when a few very large downward and upward GDP growth forecast revisions coincided with similar changes in $r_{t}^{*}$. Given the very few business cycles in our data sample, it is difficult to know whether to consider this episode as particularly informative of the correlation between $r_{t}^{*}$ and growth or more as a spurious outlier.

Although we take our regression evidence as broad confirmation that our finance-based measure of $r_{t}^{*}$ responds in a sensible way to economic news, a cautious interpretation of our results is warranted in light of recent quite negative empirical findings based on much longer spans of data. Notably, Hamilton et al. (2016) have correlated real interest rates and output growth rates in 20 different countries in samples going back as far as 1800. They find little support for the view that long-run economic growth drives changes in the equilibrium interest rate. Similarly, Lunsford and West (2017) and Leduc and Rudebusch (2014) do not find a reliable correlation between these two variables.

Instead, examinations of the historical record generally find that demographic variables

\footnotetext{
${ }^{31}$ As for the specific timing, the Blue Chip survey is generally conducted on the first two working days of each month and released on the tenth of each month, and our $r_{t}^{*}$ estimate is determined on the last business day of each month. Thus, one economic interpretation of the regression is that TIPS investors change their views partly in response to the information received during the month as reflected or released in surveys of professional forecasters such as the Blue Chip survey.
} 
have the most reliable connection with real interest rates. For example, over long samples, the fraction of the total population of working age and life expectancy appear to co-move with the real rate in ways consistent with models of aggregate saving and investment. Not surprisingly then, the link between the changing demographic structure of global economies and real interest rates has been the recent focus of much additional theoretical and empirical work (e.g., Carvalho et al., 2016, Favero et al., 2016, and Ferrero et al., 2017). In an interesting theoretical contribution, Gagnon et al. (2016, denoted GJLS) calibrate an overlapping-generations model to observed and projected changes in U.S. population, family composition, and life expectancy. They assess the effects of these changes on saving and investment and real interest rates, and their resulting calculation of the contribution of demographic factors to a lower equilibrium real interest rate is shown as the grey line in Figure $13 .{ }^{32}$ This contribution - from a calibrated theoretical model - can account for almost half of the decline in our estimated $r_{t}^{*}$ and shows a similar timing of the broad decline over the past two decades. In closely related work, Lisack et al. (2017) also calibrate an overlapping generations model to show that demographic changes alone could account for just over a 100 basis point downward trend in the U.S. equilibrium real rate from 2000 to 2015, which is broadly in line with the GJLS results.

\section{Conclusion}

Using macroeconomic models and data, many researchers have investigated the contribution to the downtrend in yields in recent decades from a falling equilibrium real interest rate. However, uncertainty about the correct macroeconomic specification has led some to question the validity of the resulting macro-based estimates of the natural rate. We sidestep this debate by introducing a finance-based measure of the equilibrium real rate that is obtained solely from dynamic term structure models estimated using the prices of inflation-indexed bonds. By adjusting for both TIPS liquidity premiums and real term premiums, we uncover investors' expectations for the underlying frictionless real short rate for the five-year period starting five years ahead. Our resulting measure of the natural rate of interest exhibits a gradual decline over the past two decades to a level of essentially zero. Furthermore, model projections suggest that the natural rate is likely to remain quite low for some time.

We view our finance-based equilibrium rate analysis as a complement to previous macrobased ones. Like the macro-based estimates, a finance-based estimate is also subject to critiques about model specification and the information content of the available data. In light of such critiques, the range of uncertainty attached to a finance-based estimate does not appear to be necessarily smaller than that surrounding the macro-based estimates. However, the underlying models and data in the two approaches are so different that the confidence intervals

\footnotetext{
${ }^{32}$ These data are from the baseline labeled "Dependent children" in Figure 8 on page 41 of GJLS.
} 
are also likely largely uncorrelated, which does suggest substantial value from constructing and comparing both finance- and macro-based estimates. Of course, a joint approach that combines macroeconomic and financial market data would appear to be particularly promising for future research. ${ }^{33}$ Indeed, our measure could be incorporated into an expanded joint macroeconomic and finance analysis - particularly with an eye towards further understanding the determinants of the lower new normal for interest rates. In this regard, Bauer and Rudebusch (2017) show that accounting for fluctuations in the natural rate substantially improves long-range interest rate forecasts and helps predict excess bond returns. In addition, future research could also be expanded along an international dimension (as in Holston et al., 2017). With a significant degree of capital mobility, the natural rate will depend on global saving and investment, so the joint modeling of inflation-indexed bonds in several countries could be informative. Finally, the issue investigated in this paper depends crucially on inference about the $\mathbb{P}$-dynamics of interest rates - which is perhaps the Achilles heal of dynamic term structure modeling. We have taken a standard approach, but other possibilities would be to incorporate survey forecast information, restrict the prices of risk, or bias adjust or shrink the dynamic parameters toward non-stationarity.

\footnotetext{
${ }^{33}$ An example of a first step toward a macro-finance approach is Joyce et al. (2012), who use a dynamic term structure model that includes survey forecasts of output growth to study U.K. long-term real rate expectations.
} 


\section{References}

Abrahams, Michael, Tobias Adrian, Richard K. Crump, Emanuel Moench, and Rui Yu, 2016, "Decomposing Real and Nominal Yield Curves," Journal of Monetary Economics, Vol. $84,182-200$.

Andreasen, Martin M., Jens H. E. Christensen, and Simon Riddell, 2018, "The TIPS Liquidity Premium," Working Paper 2017-11, Federal Reserve Bank of San Francisco.

Andreasen, Martin M., Jens H. E. Christensen, and Glenn D. Rudebusch, 2019, "Term Structure Modeling with Big Data: One-Step Estimation Using Bond Prices," forthcoming Journal of Econometrics.

Bauer, Michael D., and Glenn D. Rudebusch, 2017, "Interest Rates Under Falling Stars," Working Paper 2017-16, Federal Reserve Bank of San Francisco.

Bauer, Michael D., Glenn D. Rudebusch, and Jing (Cynthia) Wu, 2012, "Correcting Estimation Bias in Dynamic Term Structure Models," Journal of Business and Economic Statistics, Vol. 30, No. 3, 454-467.

Bernanke, Ben, 2005, "The Global Saving Glut and the U.S. Current Account Deficit," Sandridge Lecture, Richmond VA, March 10.

Bomfim, Antulio, 2001, "Measuring Equilibrium Real Interest Rates: What Can We Learn from Yields on Indexed Bonds?" FEDS Working Paper 2001-53, Federal Reserve Board.

Campbell, John Y., Robert J. Shiller, and Luis M. Viceira, 2009, "Understanding InflationIndexed Bond Markets," Brookings Papers on Economic Activity, Spring, 79-120.

Carvalho, Carlos, Andrea Ferrero, and Fernanda Nechio, 2016, "Demographics and Real Interest Rates: Inspecting the Mechanism," European Economic Review, Vol. 88, 208226.

Christensen, Jens H. E., Francis X. Diebold, and Glenn D. Rudebusch, 2011, "The Affine Arbitrage-Free Class of Nelson-Siegel Term Structure Models," Journal of Econometrics, Vol. 164, No. 1, 4-20.

Christensen, Jens H. E. and James M. Gillan, 2018, "Does Quantitative Easing Affect Market Liquidity?," Working Paper 2013-26, Federal Reserve Bank of San Francisco.

Christensen, Jens H. E., Jose A. Lopez, and Glenn D. Rudebusch, 2010, "Inflation Expectations and Risk Premiums in an Arbitrage-Free Model of Nominal and Real Bond Yields," Journal of Money, Credit and Banking 42, No. 6, 143-178. 
Christensen, Jens H. E., Jose A. Lopez, and Glenn D. Rudebusch, 2015, "A ProbabilityBased Stress Test of Federal Reserve Assets and Income," Journal of Monetary Economics, Vol. 73, 26-43.

Christensen, Jens H. E., Jose A. Lopez, and Patrick Shultz, 2017, "Is There an On-the-Run Premium in TIPS?," Working Paper 2017-10, Federal Reserve Bank of San Francisco.

Christensen, Jens H. E. and Glenn D. Rudebusch, 2015, "Estimating Shadow-Rate Term Structure Models with Near-Zero Yields," Journal of Financial Econometrics, Vol. 13, No. 2, 226-259.

Clarida, Richard, 2014, "Navigating the New Neutral," Economic Outlook, PIMCO, November.

Clark, Todd E. and Sharon Kozicki, 2005, "Estimating Equilibrium Real Interest Rates in Real Time," The North American Journal of Economics and Finance, Vol. 16, No. 3, 395-413.

Cúrdia, Vasco, Andrea Ferrero, Ging Cee Ng, and Andrea Tambalotti, 2015, "Has U.S. Monetary Policy Tracked the Efficient Interest Rate?," Journal of Monetary Economics, Vol. $70,72-83$.

Dai, Qiang and Kenneth J. Singleton, 2000, "Specification Analysis of Affine Term Structure Models," Journal of Finance, Vol. 55, No. 5, 1943-1978.

Dai, Qiang, Kenneth J. Singleton, and Wei Yang, 2004, "Predictability of Bond Risk Premia and Affine Term Structure Models," Manuscript, Stanford University.

D'Amico, Stefania, Don H. Kim, and Min Wei, 2018, "Tips from TIPS: The Informational Content of Treasury Inflation-Protected Security Prices," Journal of Financial and Quantitative Analysis, Vol. 53, No. 1, 243-268.

Del Negro, Marco, Domenico Giannone, Marc P. Giannoni, and Andrea Tambalotti, 2017, "Safety, Liquidity, and the Natural Rate of Interest," Brookings Papers on Economic Activity, Spring 2017, 235-294.

Driessen, Joost, Theo E. Nijman, and Zorka Simon, 2016, "The Missing Piece of the Puzzle: Liquidity Premiums in Inflation-Indexed Markets," Manuscript. Department of Finance, Tilburg University.

Dudley, William C., Jennifer Roush, and Michelle Steinberg Ezer, 2009, "The Case for TIPS: An Examination of the Costs and Benefits," Federal Reserve Bank of New York Economic Policy Review, Vol. 15, No. 1, 1-17. 
Duffee, Gregory R., 2002, "Term Premia and Interest Rate Forecasts in Affine Models," Journal of Finance, Vol. 57, No. 1, 405-443.

Duffie, Darrell and Rui Kan, 1996, "A Yield-Factor Model of Interest Rates," Mathematical Finance, Vol. 6, No. 4, 379-406.

Eggertsson, Gauti B., Neil R. Mehrotra, Sanjay R. Singh and Lawrence H. Summers, 2016, "A Contagious Malady? Open Economy Discussions of Secular Stagnation," IMF Economic Review Vol. 64, No. 4, 581-634.

Favero, Carlo A., Arie E. Gozluklu, and Haoxi Yang, 2016, "Demographics and the Behavior of Interest Rates," IMF Economic Review, Vol. 64, No. 4, 732-776.

Federal Reserve Board, 2018, Monetary Policy Report, February 23, Board of Governors of the Federal Reserve System.

Ferrero, Giuseppe, Marco Gross, and Stefano Neri, 2017, "On Secular Stagnation and low interest rates: Demography Matters," Working Paper 2088, European Central Bank.

Fisher, Stanley, 2016, "Why Are Interest Rates So Low? Causes and Implications," Speech at the Economic Club of New York, New York, New York, October 17, https://www.federalreserve.gov/newsevents/speech/fischer20161017a.htm.

Fleckenstein, Mathias, Francis A. Longstaff, and Hanno Lustig, 2014, "The TIPS-Treasury Bond Puzzle," Journal of Finance, Vol. 69, No. 5, 2151-2197.

Fleming, Michael J. and Neel Krishnan, 2012, "The Microstructure of the TIPS Market," Federal Reserve Bank of New York Economic Policy Review, Vol. 18, No. 1, 27-45.

Fontaine, Jean-Sébastien and René Garcia, 2012, "Bond Liquidity Premia," Review of Financial Studies, Vol. 25, No. 4, 1207-1254.

Gagnon, Etienne, Benjamin K. Johannsen, and David Lopez-Salido, 2016, "Understanding the New Normal: The Role of Demographics," Finance and Economics Discussion Series 2016-080. Washington: Board of Governors of the Federal Reserve System, http://dx.doi.org/10.17016/FEDS.2016.080.

Greenspan, Alan, 2005, Federal Reserve Board's Semiannual Monetary Policy Report to the Congress, Testimony to the U.S. Senate, February 16.

Grishchenko, Olesya V. and Jing-Zhi Huang, 2013, "Inflation Risk Premium: Evidence from the TIPS Market," Journal of Fixed Income, Vol. 22, No. 4, 5-30. 
Gürkaynak, Refet S., Brian Sack, and Jonathan H. Wright, 2007, "The U.S. Treasury Yield Curve: 1961 to the Present," Journal of Monetary Economics, Vol. 54, No. 8, 22912304 .

Gürkaynak, Refet S., Brian Sack, and Jonathan H. Wright, 2010, "The TIPS Yield Curve and Inflation Compensation," American Economic Journal: Macroeconomics, Vol. 2, No. 1, 70-92.

Hall, Robert E., 2016, "The Role of the Growth of Risk-Averse Wealth in the Decline of the Safe Real Interest Rate," Manuscript, Stanford University.

Hamilton, James D., Ethan S. Harris, Jan Hatzius, and Kenneth D. West, 2016, "The Equilibrium Real Funds Rate: Past, Present, and Future," IMF Economic Review, Vol. 64, No. 4, 660-707.

Holston, Kathryn, Thomas Laubach, and John C. Williams, 2017, "Measuring the Natural Rate of Interest: International Trends and Determinants," Journal of International Economics 108, May, S59-S75.

Hu, Grace Xing, Jun Pan, and Jiang Wang, 2013, "Noise as Information for Illiquidity," Journal of Finance, Vol. 68, No. 6, 2341-2382.

Johannsen, Benjamin K. and Elmar Mertens, 2016, "A Time Series Model of Interest Rates with the Effective Lower Bound," Finance and Economics Discussion Series 2016-033, Washington: Board of Governors of the Federal Reserve System.

Joyce, Michael A. S., Iryna Kaminska, and Peter Lildholdt, 2012, "Understanding the Real Rate Conundrum: An Application of No-Arbitrage Models to the U.K. Real Yield Curve," Review of Finance, Vol. 16, No. 3, 837-866.

Kaminska, Iryna, and Gabriele Zinna, 2014, "Official Demand for U.S. Debt: Implications for U.S. Real Interest Rates," IMF Working Paper 14/66, Washington: International Monetary Fund.

Kiley, Michael T., 2015, "What Can the Data Tell Us About the Equilibrium Real Interest Rate?," Finance and Economics Discussion Series 2015-077, Board of Governors of the Federal Reserve System.

Kim, Don H. and Kenneth J. Singleton, 2012, "Term Structure Models and the Zero Bound: An Empirical Investigation of Japanese Yields," Journal of Econometrics, Vol. 170, No. $1,32-49$. 
Laubach, Thomas and John C. Williams, 2003, "Measuring the Natural Rate of Interest," Review of Economics and Statistics, Vol. 85, No. 4, 1063-1070.

Laubach, Thomas and John C. Williams, 2016, "Measuring the Natural Rate of Interest Redux," Business Economics, Vol. 51, No. 2, 57-67.

Leduc, Sylvain, and Glenn D. Rudebusch, 2014, "Does Slower Growth Imply Lower Interest Rates?," FRBSF Economic Letter 2014-33 (November 10).

Lewis, Kurt F., and Francisco Vazquez-Grande, 2017, "Measuring the Natural Rate of Interest: Alternative Specifications," Finance and Economics Discussion Series 2017-059, Board of Governors of the Federal Reserve System.

Lisack, Noemie, Rana Sajedi, and Gregory Thwaites, 2017, "Demorgraphic Trends and the Real Interest Rate," Staff Working Paper No. 701, Bank of England.

Lo, Stephanie and Kenneth Rogoff, 2015, "Secular Stagnation, Debt Overhang and Other Rationales for Sluggish Growth, Six Years On," Bank for International Settlements, Working Paper No. 482.

Lubik, Thomas A., and Christian Matthes, 2015, "Calculating the Natural Rate of Interest: A Comparison of Two Alternative Approaches," Federal Reserve Bank of Richmond Economic Brief, EB15-10.

Lunsford, Kurt G., and Kenneth D. West, 2017, "Some Evidence on Secular Drivers of U.S. Safe Real Rates," Federal Reserve Bank of Cleveland, working paper no. 17-23.

Nechio, Fernanda, and Glenn D. Rudebusch, 2016, "Has the Fed Fallen behind the Curve This Year?," FRBSF Economic Letter 2016-33 (November 7).

Orphanides, Athanasios, and John C. Williams, 2002, "Robust Monetary Policy Rules with Unknown Natural Rates," Brookings Papers on Economic Activity 2002(2), 63-145.

Pescatori, Andrea and Jarkko Turunen, 2016, "Lower for Longer: Neutral Rate in the U.S.," IMF Economic Review, Vol. 64, No. 4, 708-731.

Pflueger, Carolin E. and Luis M. Viceira, 2016, "Return Predictability in the Treasury Market: Real Rates, Inflation, and Liquidity," in Handbook of Fixed-Income Securities, edited by P. Veronesi, Wiley, Hoboken, N.J., pp. 191-209 (Chapter 10).

Rachel, Lukasz, and Thomas D Smith, 2015, "Secular Drivers of the Global Real Interest Rate," Staff working paper 571, Bank of England. 
Rudebusch, Glenn D., 1993, "The Uncertain Unit Root in Real GNP," American Economic Review, Vol. 83, 264-272

Rudebusch, Glenn D., 2001, "Is the Fed Too Timid? Monetary Policy in an Uncertain World," Review of Economics and Statistics, Vol. 83, No. 2, 203-217.

Rudebusch, Glenn D. and Lars Svensson, 1999, "Policy Rules for Inflation Targeting," In Monetary Policy Rules, ed. by John Taylor, Chicago: University of Chicago Press, 203-246.

Rudebusch, Glenn D. and Eric Swanson, 2011, "The Bond Premium in a DSGE Model with Long-Run Real and Nominal Risks," American Economic Journals: Macroeconomics, Vol. 4, No. 1, 105-43.

Sack, Brian and Robert Elsasser, 2004, "Treasury Inflation-Indexed Debt: A Review of the U.S. Experience," Federal Reserve Bank of New York Economic Policy Review, Vol. 10, No. 1, 47-63.

Summers, Lawrence H., 2014, "U.S. Economic Prospects: Secular Stagnation, Hysteresis, and the Zero Lower Bound," Business Economics, Vol. 49, No. 2, 65-73.

Summers, Lawrence H., 2015, "Demand Side Secular Stagnation," American Economic Review, Papers and Proceedings Vol. 105, No. 5, 60-65.

Taylor, John B., and Volker Wieland, 2016, "Finding the Equilibrium Real Interest Rate in a Fog of Policy Deviations," Discussion paper 11264, Centre for Economic Policy Research.

Yellen, Janet, 2015, "Normalizing Monetary Policy: Prospects and Perspectives," Speech at the Federal Reserve Bank of San Francisco, San Francisco, California, March 27, 2015. 